\title{
Dolomite overgrowths suggest a primary origin of cone-in-
} cone

\begin{tabular}{|r|l|}
\hline Journal: & Geological Magazine \\
\hline Manuscript ID & GEO-16-1483.R1 \\
\hline Manuscript Type: & Article \\
\hline Date Submitted by the Author: & 07-Jul-2016 \\
\hline Complete List of Authors: & $\begin{array}{l}\text { Hooker, John; University of Oxford, Earth Sciences } \\
\text { Cartwright, Joe; University of Oxford, Earth Sciences }\end{array}$ \\
\hline Keywords: & Cone-in-cone, Calcite, Dolomite, Diagenesis, SEM \\
\hline & \\
\hline
\end{tabular}

SCHOLARONE ${ }^{\text {M }}$

Manuscripts 


\title{
Dolomite overgrowths suggest a primary origin of cone-in-cone
}

\author{
John N. Hooker \\ Department of Earth Sciences \\ University of Oxford \\ (+44) 1865272062 \\ South Parks Road \\ Oxford \\ OX1 3AN \\ UK \\ john.hooker@earth.ox.ac.uk \\ Joe Cartwright \\ Department of Earth Sciences \\ University of Oxford \\ (+44) 1865282525 \\ South Parks Road \\ Oxford \\ OX1 3AN \\ UK \\ joe.cartwright@earth.ox.ac.uk \\ Running title: Primary origin of cone-in-cone
}




\section{Dolomite overgrowths suggest a primary origin of cone-in-cone}

2 Abstract - A long-debated aspect of cone-in-cone structures is whether the mineral aggregates 3 composing the structure precipitated with their conical form (primary cone-in-cone), or whether the 4 cones formed after precipitation (secondary cone-in-cone). A calcite deposit from the Cretaceous of

5 Jordan bears all the defining characteristics of the structure. Trace dolomite within the sample

6 supports the primary cone-in-cone hypothesis. The host sediment is a biosiliceous mudstone

7 containing abundant rhombohedral dolomite grains. Dolomite rhombohedra are also distributed

8 throughout the calcite of the cone-in-cone. The rhombohedra within the calcite locally have dolomite

9 overgrowths that are aligned with calcite fibres. Evidence that dolomite co-precipitated with calcite,

10 and did not replace calcite, includes (i) preferential downward extension of dolomite overgrowths, in

11 the presumed growth-direction of the cone-in-cone, from the dolomite grains on which they nucleate,

12 and (ii) planar, vertical borders between dolomite crystals and calcite fibres. Because dolomite

13 overgrows host-sediment rhombohedra and forms part of the cones, it follows that the host-sediment

14 was incorporated into the growing cone-in-cone as the calcite precipitated, and not afterward. The

15 host-sediment was not injected into the cone-in-cone along fractures, as the secondary-origin theory

16 suggests. This finding implies that cone-in-cone in general does not form over multiple stages, and

17 thus has greater potential to preserve the chemical signature of its original precipitation.

18 Key words: cone-in-cone, calcite, dolomite, diagenesis, SEM

\section{Introduction}

Descriptions of cone-in-cone and arguments over its genesis date back to the $18^{\text {th }}$ Century. The common characteristic that defines the structure is that it is an accumulation of a mineral (usually calcite) comprising fibrous or bladed crystals which form conical aggregates within a rock. The cones are demarcated by fine-grained material, which is usually compositionally similar to the host-rock. Cone-in-cone is commonly found in nodular or vein-like accumulations, of $\mathrm{mm}$ to $\mathrm{cm}$-scale thickness,

25 that extend parallel to bedding in mudrocks; the cone apices point upward or downward. Most important among several unresolved questions is whether the mineral was precipitated with its conic 
27 morphology or whether that morphology developed after precipitation (Fig. 1). Following the

28 terminology of Selles-Martinez (1994), the former hypothesis is here referred to as primary cone-in-

29 cone, and the latter, secondary cone-in-cone. The further division of putative genetic mechanisms into

30 brittle and non-brittle classes (Selles-Martinez, 1994) is subordinate to the question of the basic

31 paragenetic sequence, and is addressed in the Discussion.

32 The primary hypothesis suggests that the strands of host-material that demarcate the cones were 33 included into the cone-in-cone as it grew (Cole, 1893; Richardson, 1923; Woodland, 1964; Franks, 34 1969; Maher, Ogata \& Braathen, 2016). Petrographic evidence in favor of primary cone-in-cone 35 includes the observation that the host rock and the host-material strands commonly have a similar 36 composition, and that the framework of rigid grains in the host rock appears to be 'expanded' within

37 the cone-in-cone (Franks, 1969), as though pushed apart by the precipitating calcite.

38 The secondary hypothesis implies that the host-material strands were injected into the mineral deposit 39 after deposition, and thus that the strands represent later conical partings or fractures within an 40 originally non-conic mineral body (Tarr, 1932; Gilman \& Metzger, 1967; Selles-Martinez, 1994;

41 Kowal-Linka, 2010; Ábalos \& Elorza, 2011). Petrographic evidence in favor of secondary cone-in-

42 cone is mainly based on the observation that the host-material strands commonly appear to offset the 43 cones and may be surrounded by pressure-solution residue and slickensides (Tarr, 1932).

44 Thus petrographic evidence has, to date, lent scant and ambivalent support to the two hypothetical 45 origins of cone-in-cone. Conceptually, both of these competing hypotheses are plagued by the lack of 46 an explanation of the conic shape. For primary cone-in-cone, it remains unknown why a trigonal 47 mineral with a fibrous or bladed habit should form cones. The conic angle can vary widely from 48 sample to sample. Typical conic angles range from 50 to $70^{\circ}$, but Woodland (1964) and Franks (1969)

49 note a wider conic angle, up to $\sim 100^{\circ}$, in coarser-grained host material. Both of those studies 50 concluded that the conic angle is therefore unrelated to the rhombohedral cleavage of calcite.

51 Kolokol'tsev (2002) suggested that thermal convection currents during mineral precipitation could 52 result in conical crystalline bodies, but this idea remains difficult to demonstrate empirically. Selles- 
53 Martinez (1994) argued that secondary conical fractures form in response to an overburden stress

54 transferred onto carbonate nodules formed within previously overpressured muds, and that the

55 fractures are conical because the horizontal stresses are tectonically relaxed and therefore isotropic. A

56 more intuitive and widely recognised fracture-trace pattern, which is thought to originate within such

57 stress fields, is the polygonal arrangement observed in desiccated mud (Kindle, 1917), dolomitised

58 mudstones (Bellamy, 1977), cooled basalts (Aydin \& DeGraff, 1988) and faulted fine-grained passive

59 margin sequences (Cartwright, 2011). The development of polygonal fracture arrangements can be

60 explained by the mutual abutting of poorly aligned cracks (Hornig, Sokolov \& Blumen, 1996); no

61 similarly satisfying explanation for conical fractures in flat-lying sediments is known to the authors.

62 Conical fractures could hypothetically form by volumetric expansion during the transition of

63 aragonite to calcite (Gilman \& Metzger, 1967), fluid expulsion during syneresis of gels (Aso, Gisbert

$64 \&$ Garcés, 1992) or by surface seismic waves (Ábalos \& Elorza, 2011). Although these mechanisms

65 remain speculative, a modern consensus has developed in support of the secondary hypothesis

66 (Shearman et al. 1972; Selles-Martinez, 1994; Kowal-Linka, 2010; Ábalos \& Elorza, 2011), based

67 largely on the resemblance of cone-bounding sediment strands to fractures, including their apparent

68 displacement of the cones.

69 Cone-in-cone is developed in a range of basin settings and it is important to understand in the wider context of the hydrodynamic and diagenetic evolution of the basin fills in which it occurs (Cobbold et

71 al. 2013). Cone-in-cone is commonly found in fine-grained rocks that also contain layer-parallel,

72 fibrous calcite veins. Cone-in-cone, and layer-parallel calcite veins in general, can potentially reveal

73 information about the stress history of sedimentary basins. Such structures displace the host-material

74 vertically; this observation has been invoked as evidence for anomalous pore pressures during

75 compaction (Hillier \& Cosgrove, 2002; Cobbold \& Rodrigues, 2007). If cone-in-cone is secondary,

76 then one or more of the many potential secondary fracture mechanisms mentioned above may also

77 have acted upon the host rock. The lack of agreement about the basic kinematic evolution of cone-in-

78 cone (Fig. 1) is a barrier to evaluating these wide ranging putative genetic mechanisms. 
79 Cone-in-cone, and calcite veins and nodules in general, can also potentially record the fluid-chemical

80 evolution of sedimentary basins. Isotopic analyses of cone-in-cone to date support early diagenetic

81 (tens of metres of burial-Israelson, Halliday \& Buchardt, 1996; McBride, Picard \& Milliken, 2003;

82 Kowal-Linka, 2010) to late diagenetic (hundreds of meters to $\sim 3$ kilometers of burial-Marshall,

83 1982; Hendry, 2002; Parnell et al., 2013) formation. The origin of cone-in-cone is of principal interest

84 to such investigations. If primary, then cone-in-cone has a greater potential for preserving the original

85 chemical signature of the fluid in which it formed. If secondary, the chemistry of the structure might

86 reflect a mixture of the original precipitation fluid as well as later fluids that were present during its

87 polyphase development.

88 The aim of this paper is to present critical new petrographic evidence that strongly supports the

89 primary-origin hypothesis. This evidence comes from a cone-in-cone sample recovered from

90 subsurface core drilled in Jordan. Although this study is based on a single interval in one core, it is

91 shown in the Sample description section that this sample includes all the previously described,

92 defining characteristics of cone-in-cone. In the Discussion, it is therefore argued that the inferences

93 made regarding the formation of this sample are applicable to cone-in-cone in general. It is also

94 argued that structures previously used to support a secondary origin, such as striations and surfaces

95 containing pressure-solution residue, can often just as easily be interpreted as overprinted structures.

\section{2. Geologic setting}

97 The present study is based on an example from core recovered from Cretaceous strata in central

98 Jordan (Fig. 2). The core interval containing the cone-in-cone is from the stratigraphic equivalent of

99 the Muwaqqar Formation, a mudrock succession identified as Maastrichtian in age in southern and

100 central Jordan (Powell \& Moh'd, 2011) and as young as Eocene-age toward the north, based on

101 microfossil assemblages (Alqudah et al. 2014). The Cretaceous and Paleogene of Jordan were

102 deposited as a northward-prograding basin fill along the Tethyan margin. The Muwaqqar Formation is

103 an immature source-rock, containing in excess of $20 \mathrm{wt} \% \%$ organic carbon in some intervals (Ali

104 Hussein et al. 2014a). 
105 The Cretaceous-Paleogene strata were deposited in the Sirhan Basin upon NW-SE striking active

106 normal faults (Abu-Jaber, Kimberley \& Cavaroc, 1989; Beydoun, Futyan \& Jawzi, 1994). The core

107 site is on the north-eastern margin of the Sirhan graben system, in the footwall of a major graben-

108 bounding normal fault (Fig. 2). Regional-scale tectonism during the Late Cretaceous was dominated

109 by horizontal shortening and arch formation associated with the closure of the Tethys Ocean (Eyal \&

110 Reches, 1983; Abu-Jaber, Kimberley \& Cavaroc, 1989). Local extension from normal-fault motion in

111 the Sirhan Basin accommodated sedimentary basin-fill and resulted in growth faulting and re-working

112 of sediments (Alqudah et al. 2014).

113 Cone-in-cone calcite is present within cores drilled throughout the Sirhan Basin (Ali Hussein et al.

114 2014b). However, cone-in-cone intervals are rare within cores; no more than three to four have been

115 observed within any single core that penetrates the entire Muwaqqar Formation, which is typically at

116 least $200 \mathrm{~m}$ thick. Cores, outcrops, and mine exposures of the Belqa Group throughout northern

117 Jordan contain abundant nodular carbonates (e.g., Abed \& Amireh, 1983; Abed \& Al-Agha, 1989;

118 Pufahl et al. 2003) but to our knowledge the core descriptions of Ali Hussein et al. (2014b) are the

119 first identification of cone-in-cone in the Belqa Group.

120 The core interval described here (Fig. 3) was recovered from a depth of $318 \mathrm{~m}$ below land surface.

121 Regional geologic considerations and low thermal maturity of the Muwaqqar Formation suggest a

122 moderately deeper burial, up to $1.5 \mathrm{~km}$, preceding exhumation to the current depth. Assuming a

123 typical geothermal gradient, this estimated maximum depth would correspond to a maximum

124 temperature near $70^{\circ} \mathrm{C}$. Prograde burial and exhumation of the rocks is consistent with the southerly

125 advance of Alpine shortening (Abu-Jaber, Kimberley \& Cavaroc, 1989).

126 The approximated maximum temperatures might have been reached amid shallower burial and

127 hydrothermal fluid circulation. However, there is no evidence for hydrothermal activity aside from

128 regional flood basalts (Bender, 1974; Beydoun, Futyan \& Jawzi, 1994). No basalt was intersected by

129 the core, and the closest basalt in outcrop is approximately $20 \mathrm{~km}$ to the east (Fig. 2).

130 3. Methods 
131 Cone-in-cone was observed in core samples and in thin section. Thin sections include standard

132 petrographic sections and sections polished for a scanning electron microscope (SEM). The SEM is an

FEI Quanta 650 field-emission gun with cathodoluminescence (CL) and energy-dispersive X-ray spectroscopy (EDS) detectors. All SEM operations were performed at $20 \mathrm{kV}$. EDS spectra were collected at $10 \mathrm{~mm}$ working distance. Qualitative EDS maps are false-coloured for calcium, magnesium, and silicon. The CL mirror geometry required a minimum working distance of $\sim 18 \mathrm{~mm}$, which was used. CL images use a large spot size and slow scan rate (6-18 hours per frame; $0.003-$ 0.01 seconds per pixel) to minimise streaking from persistent luminescence of carbonates.

Grain size measurements were made from scaled optical- and SEM-photomicrographs. Variations in

140 the abundances of rock constituents were quantified by measurement along lines of observation drawn 141 parallel to bedding.

\section{4. Sample description}

143 The cone-in-cone sample on which this study is focused is present within a biosiliceous mudstone, 144 approximately $50 \mathrm{~cm}$ thick. The host rock contains abundant dolomite rhombohedra (hereafter, 145 rhombs - Fig. 4) in a siliceous matrix. The matrix consists of amorphous organic matter and 146 microgranular silica, likely having a biogenic origin, based on local radiolaria and bedded cherts 147 elsewhere in the core. Foraminifera tests are also present but rare. Rhombs are $61 \pm 21 \mu \mathrm{m}$ in their 148 longest dimension. Rhombs have irregular boundaries that might have resulted from reworking, but it 149 is not clear whether they are detrital or authigenic. Rhombs are zoned in CL (Fig. 5). The zonation is 150 typically concentric, often including a dimly luminescent core and brighter but variable rim. Rhombs 151 compose $44 \pm 10$ percent of the host rock and $8.3 \pm 6.4$ percent of the cone-in-cone and, as described 152 below, the distribution of rhombs varies proportionally with that of the siliceous matrix.

153 The cone-in-cone interval is approximately $7 \mathrm{~cm}$ thick (Fig. 3). The upper boundary of the cone-in154 cone is gradational; the lower boundary is discrete and layer-parallel. The gradational upper boundary 155 is composed of tiny calcite lenses (lengths on the order of $10 \mu \mathrm{m}$ ) sparsely distributed throughout the 156 host rock. Moving downward, the calcite proportion increases relative to that of the host-rock. The 
157 calcite bodies comprise multiple cones, which are demarcated by strands whose composition is

158 identical to that of the rock layer that hosts the cone-in-cone (i.e., siliceous matrix with abundant

159 rhombs). Based on their composition these areas between cones are here referred to as host-rock

160 strands. Central to the later discussion will be the origin of these strands, including whether they

161 comprise remobilised host sediment.

162 Cones are mostly composed of calcite, with subsidiary dolomite. Cone apices almost uniformly point

163 upward. Rare downward-pointing cones are present underneath flat-lying strands of host rock near the

164 top gradational boundary. Larger cones are composed of smaller cones (Figs. 3, 6). Macroscopic

165 cones are typically separated from one another by host-rock strands of mm-scale thickness;

166 microscopic cones, by host-rock strands of $\mu \mathrm{m}$-scale thickness. The thinnest host-rock strands are

167 thinner than rhombs and generally contain no dolomite (Fig. 6c). The overall geometry of the cone-in-

168 cone body is unclear because of the limited sampling of the core. However, the planar lower surface

169 and gradational upper surface reflect the boundaries of small lenticular calcite bodies near the top of

170 the cone-in-cone interval (Fig. 6), having discernible cones at their base and diffuse tops. These

171 diffuse tops may be composed of cones too small to detect at the resolution of our microscopes and

172 polishing techniques.

173 Lower in the sample, layer-parallel bands transect cones (Fig. 3). The bands are seen optically to be

174 regions that vary in calcite:host-rock ratio. Rhomb density (number per unit area) is proportional to

175 the host-rock fraction (Figs. 7, 8), and so, within the calcite-rich bands, both rhombs and matrix are

176 less abundant. The rhomb:matrix ratio remains roughly constant throughout the sample, including

177 within the host-rock (Fig. 8b).

178 The bands show minor offset across macroscopic host-rock strands, but it is unclear whether this

179 offset is structural, resulting from shear along the intervening host-rock strand, or whether the bands

180 formed with slight stratigraphic offset. Both interpretations assume that the bands represent layers of

181 contemporaneously precipitated calcite (Fig. 1), whether forming a slight mismatch across strands

182 during precipitation (primary cone-in-cone) or offset afterward (secondary cone-in-cone). 
183 The calcite composing the cone-in-cone is composed of optically continuous crystals (Fig. 7). The

184 boundaries between these crystals either lie along host-rock strands or are roughly vertical and

smooth, with no space between neighbouring crystals. Thus the cone-in-cone sample can generally be regarded as fibrous, its crystals being horizontally thin and vertically long, although some crystals are

187 limited in height and so better qualify as equant. Here we refer to optically continuous parts of the cone-in-cone as crystals, which can be identified by uniform extinction in cross-polarised light (Fig.

7). The size of crystals varies throughout the cone-in-cone but is mostly consistent laterally.

Horizontal widths range from roughly $100 \mu \mathrm{m}$ to a few mm; vertical lengths reach up to $3 \mathrm{~cm}$. Crystal size generally coarsens toward the bottom, but calcite-rich, strand-poor bands are marked by smaller and more fibrous crystals.

Crystals are generally, though not exclusively, larger than the smallest cones resolvable using a light microscope; larger-scale cones are larger than crystals. Consequently, some host-rock strands are entirely enveloped within individual calcite crystals (Fig. 7), whereas other strands - generally larger ones- demarcate the boundaries between neighbouring crystals.

Host-rock strands demarcating cones have smooth undersides and corrugated (Woodland, 1964) upper sides (Fig. 9). Throughout the sample, strands dip near $55^{\circ}$ from horizontal, either to the left or right in thin section. Corrugations mark the intersections of clay rings (Gresley, 1894; Franks, 1969) with the thin section, based on the annular geometry of host-rock strands in map view (Fig. 6d). Each corrugation in the upper side of the strand consists of one edge at low angle-to-bedding and a second edge having a steep dip. These two sets of edges alternate, producing a consistently stepping corrugation (consistent corrugation) to the upper surface of the strand.

204 Cones generally either terminate within the cone-in-cone at a dipping host-rock strand, or at the bottom of the cone-in-cone interval. The bottom of the interval is macroscopically flat (Fig. 3) but 206 microscopically corrugated (Fig. 9c). The corrugation at the bottom of the cone-in-cone is referred to 207 here as inconsistent; flat-lying micro-scale surfaces are separated by steep surfaces dipping one way 208 or the other, with varying lengths, and the sequence is irregular. 
209 The sample contains rare subvertical opening-mode fractures-i.e., fractures lacking shear offset

210 (Figs. 3, 9). Each opening-mode fracture is entirely filled by inclusion-free calcite and has a width on

211 the order of $100 \mu \mathrm{m}$. Fracture calcite is in optical continuity with cone calcite. These fractures appear

212 to crosscut the cones, commonly lying along host-rock strands for some distance between vertical cuts

213 through calcite (Fig. 3). The fractures are therefore interpreted to post-date the cone-in-cone .

214 Minor dolomite is present within the calcite cones (Fig. 10). Dolomite has an equant to fibrous habit

215 similar to that of the calcite. Dolomite forms optically continuous crystals similar to those of calcite in

216 that their lateral boundaries are generally vertical. In contrast with calcite crystals, dolomite crystals

217 are smaller; most dolomite crystals are less than $300 \mu \mathrm{m}$ in their longest dimension, which is usually

218 vertical. In contrast with the dolomite rhombs described above, the dolomite crystals are bigger; recall

219 that rhombs are near $60 \mu \mathrm{m}$ in their longest dimension.

220 Cathodoluminescence of dolomite crystals shows that crystals commonly include one concentrically

221 zoned dolomite rhomb at the top of the crystal (Fig. 10). Dolomite crystals terminate downward upon

222 surfaces parallel to variably luminescent zones within the dolomite. These lower terminations of

223 dolomite crystals lie against calcite crystals; in contrast, essentially all concentrically zoned dolomite

224 rhombs within the cone-in-cone are surrounded by at least trace amounts of siliceous matrix (Fig.

$22510 \mathrm{e})$.

226 5. Interpretation

227 5.a. Direction of growth

228 In cone-in-cone samples that are symmetrical about a medial plane (i.e., nodules or layer-parallel

229 veins) the apices generally point inward, and the bases lie at the sediment:nodule interface (Cole,

230 1893; Gresley, 1894; Woodland, 1964; Marshall, 1982). In those studies it was therefore interpreted

231 that the cones grew from the apices toward the bases. As with the growth of the less-enigmatic

232 parallel-fibrous calcite veins, this interpretation is based on the assumption that calcite is added to the

233 growing vein at the sediment:vein interface, without any cracking (Bons, Elburg \& Gomez-Rivas,

234 2012). 
235 If the cone-in-cone is primary, then the asymmetry of the cone-in-cone structure described here is

236 consistent with downward growth, from the apices toward the bases. If secondary, perhaps the

237 direction of calcite growth cannot be inferred, although the gradational top and discrete bottom of the

238 structure, as well as the asymmetry of the banding, corroborate a unidirectional growth. Furthermore,

239 it is simplest to assume that the basal surface of the cone-in-cone structure remained relatively planar

240 throughout growth, though possibly with minor offset across host-rock strands, as discussed below.

241 This interpretation is supported by the roughly layer-parallel geometry of the bands, which, when they

242 precipitated, would have formed the coeval basal growth surface of the calcite structure.

\section{5.b. Origin of rhombs and their inclusion into the calcite}

244 Dolomite rhombs in the host rock are either authigenic or detrital, and if detrital, their angular form

245 indicates that they have not been transported far. If the rhombs are detrital, they pre-date the cone-in-

246 cone; if they are authigenic, they might pre-, syn-, or post-date the cone-in-cone structure.

247 We interpret that the rhombs within the cone-in-cone are the same as the rhombs within the host rock.

248 This interpretation is based on (i) the equal size of the rhombs within the cone-in-cone and host rock;

249 (ii) the similar zoning pattern (Figs. 5, 10); (iii) the constant relative abundance of rhombs and matrix

250 mud within the host-rock throughout the cone-in-cone (Fig. 8); and (iv) the presence of matrix mud

251 included around the margins of the rhombs within the cone-in-cone (Fig. 10).

252 At least three possibilities exist to explain the inclusion of the host-rock rhombs into the cone-in-cone

253 (Fig. 11). First, the inclusion may have been primary; that is, the cone-in-cone may have grown

254 around the rhombs. Second, the rhombs may have been injected into the cone-in-cone along fractures.

255 Third, rhombs may have crystallised in place after the cone-in-cone formed, regardless of whether the

256 host-material was emplaced primarily or injected along fractures. The ambiguity of the final rhomb-

257 arrangement stymies interpretation of the origin of cone-in-cone. Further evidence is therefore

258 necessary in order to eliminate any of these three possibilities.

\section{5.c. Timing of dolomite crystals}


260 Two possible explanations are considered here for the distribution of dolomite crystals that include

261 rhombs within the cone-in-cone calcite (Fig. 11). First, the dolomite crystals may be overgrowths of

262 rhombs, which grew as the cone-in-cone grew. Second, the dolomite crystals might have nucleated

263 from rhombs after the cone-in-cone formed and grown by replacing calcite. In that case, the dolomite

264 crystals post-date the cone-in-cone.

265 The second of these explanations is much less likely than the first. If the cone-in-cone was already

266 formed, and entirely composed of calcite, by the time dolomitisation commenced, then there would

267 presumably be no preferred direction in which the dolomitisation should proceed. It could be argued

268 that the host-rock strands and crystallographic boundaries would serve as barriers to dolomitisation,

269 although dolomite rhombs that replace calcite commonly transgress multiple original grains (e.g.,

270 Moss \& Tucker, 1995; Merino \& Canals, 2011). But even if crystal boundaries did halt

271 dolomitisation, there is no apparent reason why the dolomitisation should proceed preferentially

272 downward from the rhombs - in the direction in which the cone-in-cone presumably grew—and not

273 upward (Fig. 10).

274 Also, given the single dolomite-nucleation site represented by an optically-continuous rhomb, it might

275 be expected that dolomite would pseudomorphically replace the calcite crystals, such that replacement

276 dolomite would have optical continuity with the calcite crystals (Tucker \& Wright, 1990), but this is

277 not the case.

278 The observation that the dolomite crystals extend downward from an optically-continuous rhomb is

279 better explained by the first hypothesis - that dolomite overgrew rhombs while the cone-in-cone was

280 growing. Figure 12 is an interpretation of this process, consistent with the observations. The cone-in-

281 cone structure grew by adding calcite and dolomite to the basal contact with the host rock, thus from

282 the apices toward the bases as discussed above. In principle the ions composing these minerals should

283 have been delivered to the basal surface within an aqueous fluid, whether those ions were replenished

284 by fluid advection or diffused through a static fluid. As the cones grew, the host material—silicate

285 mud and dolomite rhombs — was included between the cones. Locally the dolomite rhombs would 
286 have been exposed to the basal precipitation surface. Where the rhombs were thus exposed it was

287 more thermodynamically favourable for the dissolved ions to precipitate as dolomite. That is, both

288 dolomite and calcite crystals precipitated into the pore fluid, with the mineral determined by the

289 exposed substrate.

290 Because dolomite crystals are relatively short, terminating downward against calcite crystals within

291 less than $1 \mathrm{~mm}$, it appears that calcite generally precipitated faster than dolomite. The substrate effect

292 was soon overcome by the faster growth of calcite. Perhaps dolomite growth was limited by the

293 supply of $\mathrm{Mg}^{2+}$ in solution. Alternatively, the rate of dolomite crystal growth may have been slower

294 because the host-rock dolomite rhombs already had euhedral faces upon incorporation into the cone-

295 in-cone. The calcite, in contrast, may have precipitated upon fossils or spontaneously nucleated in

296 micro-pores, but either way appears to have grown from multiple anhedral nuclei throughout the

297 growth of the cone-in-cone. Thus the calcite may have grown faster because growth is generally faster

298 on atomically rough (anhedral) surfaces (e.g., De Yoreo \& Vekilov, 2003).

299 Some dolomite crystals do not include rhombs. This could be an artefact of the thin section plane; the

300 crystal is taller and presumably, in many cases, wider than the rhomb, so the crystal has a greater

301 likelihood of intersecting the thin-section plane than does the rhomb within it. Overgrowths may

302 likewise not all extend purely vertically but rather out of the vertical thin-section plane. Alternatively,

303 there may be dolomite in the cone-in-cone that nucleated spontaneously rather than upon rhombs.

304 Regardless, the planar, vertical boundaries of such crystals suggest co-precipitation with calcite into

305 the pore fluid rather than replacement of calcite.

306 If it is accepted that the dolomite crystals that are in optical continuity with rhombs are indeed

307 overgrowths of those rhombs, then it follows that the inclusion of the rhombs into the cone-in-cone

308 was primary. If the dolomite crystals are overgrowths of rhombs and share planar, vertical boundaries

309 with the calcite crystals, then the rhombs must have been in place as the calcite grew. Therefore the

310 host-rock strands, which contain the rhombs over which the dolomite crystals grew, could not have 
311 been injected into the cone-in-cone after the calcite precipitated; rather, the calcite grew in its conical

312 form, incorporating strands of host rock as it grew. That is, the cone-in-cone is primary in origin.

\section{6. Discussion}

314 6.a. A kinematic model for primary growth of cone-in-cone

315 The textural evidence presented above demonstrates the primary origin of the present sample. We

316 believe that the primary-origin interpretation applies to cone-in-cone in general, because the

317 morphology of the host-rock strands in the present sample - a smooth lower side and a consistently

318 corrugated upper side - is characteristic of cone-in-cone in general.

319 Previous studies have noted host-rock inclusions within layer-parallel fibrous veins and interpreted

320 that the inclusions were incorporated within the veins during mineral precipitation and not afterward.

321 In examples provided by Hilgers \& Urai (2005) and Cobbold et al. (2013), the host-rock inclusions

322 form triangular trails in cross section, potentially reflecting a conical fibrous structure in 3D. In those

323 examples, the edges of host-rock inclusions fit together like puzzle pieces when translated along the

324 fibres separating them. This fact supports the interpretation of primary incorporation into the veins as

325 opposed to later injection by fracturing, during which the included host material would likely have

326 been rotated or distorted.

327 Host-rock strands within the present sample are not so easily reassembled to their original geometry,

328 owing to the minuscule widths of many host-rock strands - particularly the thin matrix inclusions

329 interspersed among relatively coarse rhombs (Figs. 6, 7, 9, 10b). Lacking such visually reconstructible

330 geometry for corrugated host-rock strands, which are characteristic of classical cone-in-cone, we

331 propose the following interpretation for how corrugations develop.

332 Inconsistent corrugation forms as rows of cones grow at the bottom surface of the structure. These

333 cones are not perfectly side-by-side and so the bottom surface is rough; this roughness is inconsistent

334 corrugation. Similarly, consistent corrugation forms as cones grow downward against the tilted

335 surface of an underlying cone (Fig. 12). That the lower cone halts the growth of the upper cone is 
336 evident by the full conic shapes of cones that reach the bottom surface versus the incomplete cones of

337 those upsection. These incomplete cones can be considered to correspond to the conic scales of

338 Gresley (1894).

339 If the cone-in-cone grew downward, then where neighbouring cones meet, that cone which extends

340 even slightly more downsection will halt the growth of the more upsection cone. Because

341 macroscopic cones grow by the addition of microscopic cones forming in inconsistently corrugated

342 rows, the halting of a macroscopic cone is achieved by the 'backstepping' of these rows of

343 microscopic cones (Fig. 12). The lower of these two macroscopic cones will continue to grow

344 downward, by the addition of another row of microscopic cones in an uninterrupted conical array,

345 whereas the upper macroscopic cone will step backward from the lower cone. This stepping is

346 represented by the shortening of each successive row by one or more discrete microscopic cones,

347 because there is insufficient space for microscopic cones to grow. The uninterrupted upper surface of

348 the lower (macroscopic) cone forms the smooth underside of the host-rock strand. The progressive

349 backstepping of the upper (macroscopic) cone produces the consistently corrugated upper-side of the

350 host-rock strand. Therefore the growth of cones against the horizontal basal surface produces

351 inconsistent corrugation, but the growth of cones against the tilted top of an underlying cone produces

352 consistent corrugation (Fig. 13).

353 The physical mechanism for conical calcite growth remains unexplained, as do the factors controlling

354 the width of host-rock strands. The basis of this conical-interference growth model is the combined

355 simplicity of its rules and thorough accounting for the salient characteristics of cone-in-cone. Below

356 we speculate about the physical processes involved.

\section{6.b. Previous arguments for primary cone-in-cone}

358 The interpretation that cone-in-cone is primary is supported by several other, arguably weaker, lines

359 of evidence, many of which have been presented by previous workers. For example, cone-in-cone is

360 said to have a primary origin because the cone-in-cone expands the detrital framework of the host

361 sediment (Franks, 1969). This expansion is apparent in Jordan by the sparse distribution of rhombs 
362 (Fig. 7), as well as rare foraminifera tests (Fig. 6c), in proportion to the matrix included within the

363 calcite cones (Fig. 8). The secondary cone-in-cone hypothesis suggests that the framework grains

364 were injected into fractures within the calcite after the calcite was precipitated. It is difficult to

365 envision how such large, rigid particles could have been injected into the calcite along 'fractures' as

366 narrow as the thinnest host-rock strands. Such an injection would have preferentially emplaced matrix

367 mud into the narrowest fractures, resulting in a lower abundance of rigid grains within the host-rock

368 strands, relative to that abundance in the host-rock outside the cone-in-cone. But the abundance of

369 rhombs is equal in the host rock and the strands. It is thus more reasonable to interpret the strands as

370 primary inclusions of the host material than as fractures. (It may be that the rhombs post-date this

371 hypothetical host-sediment injection (Fig. 11) and that we are incorrect in our interpretation of the

372 dolomitisation, but the foraminifera certainly pre-date the cone-in-cone and would therefore have to

373 have been injected).

374 The separation of calcite crystals by host-rock strands is likewise difficult to attribute to fracturing.

375 The extinction angles of calcite crystals can vary markedly across even the most inconspicuous host-

376 rock strands (Fig. 7). If fracturing created significant mismatch of crystallographic axes within an

377 originally optically-continuous calcite body, then we would expect to see evidence of rotation of the

378 calcite blocks on either side of the fracture, such as brecciation or progressive rotation of axes with

379 increasing distance from the fractures. There is neither such evidence present, nor is there evidence of

380 crystal strain, as from non-uniform extinction. It is conceivable that a hypothetical fracture-invoked

381 by the secondary cone-in-cone hypothesis - injecting host-material between pre-existing crystals

382 could have propagated along a weakness represented by the crystallographic boundary, but in that

383 case the conical boundaries would be primary. Instead, the simplest explanation for the bounding of

384 crystals by host-rock strands was given by Richardson (1923), who observed that calcite fibres

385 terminate against host-rock strands, rather than being cut by the strands. The crystals (or fibres, in the

386 case of Richardson, 1923) were originally and always separated by the host-rock strand. The crystals

387 formed on either side of the host-rock strand, which was included between the cones as the calcite

388 precipitated. 
389 Nonetheless, thicker strands are more likely to juxtapose misoriented crystals. As such, thin strands 390 can be included within relatively large, optically continuous calcite crystals (Fig. 7). Presumably, the 391 smallest-scale cones template crystallographically upon extant cones upsection and nonetheless ensconse host-material in between. It is interesting that the cones take on a scale-free aspect (Figs. 6,

$3939,12 \mathrm{c}$ ) despite a strand-size dependence of crystallographic continuity. This observation supports the 394 view, previously stated, that calcite crystallography is likely unimportant for conic pattern formation 395 (Tarr, 1922; Woodland, 1964; Franks, 1969). That is, strands can be included between or within 396 crystals, with no difference in the morphology of the strand.

Maher, Ogata \& Braathen (2016) pointed out that the cone-bounding host-rock strands generally dip at a steeper angle than would be expected for thrust-displacement faults, according to Andersonian faulting theory. Indeed, cone-demarcating strands within the present sample, and nearly all documented examples, dip more steeply than $45^{\circ}$, for which we would expect a maximum compressive stress that is vertical, and a normal sense of displacement.

402 A final argument is that the shapes of the host-rock strands toward the top of the sample (Fig. 6a, c) 403 are difficult to interpret as fractures. The strands have a straight edge that overlies the tilted upper 404 surface of underlying cones, thus a roughly triangular overall shape. If such a strand is a fracture, it 405 would be expected to have a roughly parallel, albeit possibly corrugated, opposite edge. It is simpler 406 to interpret the fine-grained material in Figure 6 as the negative space between multiple separate 407 cones. This interpretation is further supported by the horizontal disk-shapes of the smallest aggregates 408 of cones within the strands (Fig. 6a, b). If the host-rock strands are fractures, then these disks within 409 the strands appear to post-date the fractures; otherwise the disks should have been rotated somewhat 410 from horizontal upon injection. But because these disks themselves are formed of cones, there must 411 have been multiple calcite-precipitation and conical-fracturing events, presumably all while the 412 sediment was plastic. On the other hand, if the cone-in-cone is primary, then all the calcite cones 413 would have formed during a single, if protracted, phase of growth. 
415 If the present interpretation is correct, then the purported secondary mechanisms which injected host

416 material and formed the cones, mentioned in the Introduction, are not necessary to the formation of

417 cone-in-cone. Therefore these mechanisms should not be interpreted to have occurred in rocks bearing

418 cone-in-cone without further evidence.

419 Furthermore, the apparent vertical displacement of the host material in our core sample by the cone-

420 in-cone implies that the vertical compressive effect of the overburden was counterbalanced during

421 calcite precipitation, whether by static fluid overpressure (Sellés-Martínez, 1996; Hillier \& Cosgrove,

422 2002) seepage forces (Cobbold \& Rodrigues, 2007; Maher, Ogata \& Braathen, 2016), or the force of

423 crystallisation (Richardson, 1923; Franks, 1969). Stress and fluid pressure conditions favouring cone-

424 in-cone formation could have been present early, during shallow burial and thus low overburden

425 stress; during deep burial and strong fluid overpressure; or late, during exhumation. That previous

426 geochemical studies have led to inferred burial depths ranging from tens to thousands of meters, as

427 mentioned in the Introduction, suggests that cone-in-cone does indeed form under a variety of burial

428 conditions in nature.

429 Previous studies invoked the unconsolidated nature of the sediment as being important to cone-in-

430 cone formation, based on the compacted appearance of clay inclusions (Woodland, 1964), contortion

431 of the enclosing material (Franks, 1969) and cone-in-cone being systematically crosscut by brittle

432 structures (Maher, Ogata \& Braathen, 2016). Within the present sample, the narrowest host-rock

433 strands are narrower than the rhomb widths and contain no dolomite. Therefore we infer that the

434 rupture of host material, along surfaces now enveloping calcite, occurred only within the matrix and

435 did not cleave rhombs. This pattern would be expected if the rhombs and foraminifera were relatively

436 rigid and the matrix poorly consolidated.

437 However, poor bonding between microscopic silicate grains and organic material in the matrix,

438 relative to the bonds within carbonate mineral lattices, could maintain such a mechanical contrast

439 even down to metamorphic depths. Moreover, the constancy of the rhomb:matrix ratio, throughout the

440 cone-in-cone and host rock, suggests that the growth of calcite did not deform the host material via 
441 grain-boundary sliding. If the matrix had behaved as a fluid during cone-in-cone formation, such that 442 pressure exerted upon the rigid rhombs could displace them with respect to the matrix, then we might 443 expect to see a greater proportion of matrix within the strands demarcating the cones, and a 444 corresponding greater proportion of rhombs surrounding the cone-in-cone. We conclude that, 445 although the matrix was weaker than the rhombs, the matrix was nonetheless sufficiently consolidated 446 as to be spatially coupled with the framework grains during displacive growth of calcite. An 447 effectively solid matrix is also consistent with the vein-like geometry of many cone-in-cone samples 448 (Cobbold et al. 2013; Le Breton, Cobbold \& Zanella, 2013; Parnell et al. 2013; Maher, Ogata \& 449 Braathen, 2016).

450 We still lack a satisfactory explanation for the conic shape. However, the interpretation that cone-in451 cone is an amalgamation of crystalline bodies, separated since precipitation by host-rock strands, 452 suggests that that conic morphology develops as a result of the interfering, space-filling growth of 453 those crystalline bodies, as conceptually illustrated in Figure 12. We speculate that the final conic 454 pattern arises from either (i) the initial arrangement of the nucleation sites, which presumably are 455 either pore spaces or carbonate fragments within some stratum, or (ii) the deformation of the host 456 material as individual bodies grow, which could trigger new bodies to grow in the vicinity of extant 457 ones. This latter process is akin to the notion that growing fractures may dynamically produce en 458 échelon arrays (Olson \& Pollard, 1991), with host-rock strands or septae intervening.

\section{6.d. Secondary cone-in-cone, or overprinted deformation?}

460 The present sample refutes other arguments in favor of secondary cone-in-cone. It has been argued 461 that offset of growth bands along host-rock strands shows that shearing is involved in the formation of 462 cone-in-cone (Tarr, 1932; Kowal-Linka, 2010). The bottom surface of the present sample, which is 463 interpreted as a surface of coeval precipitation, is uneven across the host-rock strand. No shearing 464 needs to be invoked to explain this offset; the offset is primary to the assemblage of the structure. The 465 lower part of the surface belongs to the lower cone; the upper cone grows downward against the lower 466 cone, creating the corrugations along the intervening host-rock strand (Figs. 12, 13). 
467 Importantly, in other samples there may be superimposed shear between cones, as primary host-rock 468 strands might serve as long-term surfaces of weakness within a rigid calcite body. Such weakness is 469 consistent with the tendency for later fractures to propagate along host-rock strands (Figs. 3, 9). But 470 such superimposed deformation has nothing to do with the origin of cone-in-cone. The same argument 471 holds for related structures within cone-in-cone samples that have been suggested as vital to its 472 formation, including pressure-solution residues and slickensides within cone-bounding clay rings 473 (Tarr, 1932), and apparent shear fractures between cones (Durrance, 1965; Gilman \& Metzger, 1967), 474 here interpreted as primary-growth corrugations. There is no evidence in the Jordan sample of 475 pressure solution or any secondary, brittle deformation associated with the formation of the cones.

476 It is of course possible that different mechanisms may produce similar structures - that other cone-in-

477 cone examples may have formed by secondary deformation, including recrystallisation, of non-

478 conical calcite (or aragonite) bodies. There is an interesting similarity between the dolomite crystals

479 here and the 'straightened rhombohedra' of Aso, Gisbert \& Garcés (1992). That study noted cone-in480 cone fibres that represent assemblages of rhombohedral calcite crystals. Those authors suggested that 481 such fibres formed by alignment of rhombohedra into fibres from an organic gel parent-phase, with 482 conical cracking as a by-product. Important differences between those fibres and the dolomite crystals 483 investigated here include the latter sample having (i) commonly only a single rhombohedron in each 484 crystal and (ii) abundant chemically and morphologically identical rhombohedra in the host rock.

485 Still, the common observation of rhombohedra serving to align crystals composing cone-in-cone, 486 mutatis mutandis, is compelling.

\section{7. Conclusions}

488 A cone-in-cone sample from Jordan includes all the distinguishing characteristics of the structure, 489 including crystalline composition, horizontal attitude with vertical cones in a fine-grained sedimentary 490 host, and cones demarcated by strands of fine-grained material. In this sample, the host-rock contains 491 abundant dolomite rhombohedra, in equal abundance outside the cone-in-cone and within the strands 492 that demarcate the cones. The cones include dolomite crystals, which are interpreted to be 
493 overgrowths of dolomite rhombohedra and which appear to have formed during the growth of the

494 cone-in-cone. These interpretations are based on the dolomite crystals' (i) having optical continuity

495 with the rhombohedra and not with neighbouring calcite fibres, (ii) having an equant-fibrous habit,

496 like that of the calcite composing the cone-in-cone, and (iii) extending systematically downward from

497 the rhombohedra, in the apparent direction of growth of the cone-in-cone. The rhombohedra were

498 therefore in place as the cone-in-cone grew. This means that the cone-in-cone is a primary structure-

499 that it incorporated host material and formed its conic shape as the calcite precipitated, and not

500 afterward.

501 Consistent with this interpretation are: host-rock strands with non-parallel edges, suggesting the

502 strands are not fractures; rigid grains (dolomite rhombohedra and foraminifera tests) ensconced in the

503 calcite cones, suggesting the grains were not injected along narrow fractures; and mismatched

504 crystallographic orientation of calcite crystals across host-rock strands, suggesting that the crystals

505 grew independently and were never a single, continuous crystal. Previous studies ascribing the

506 formation of cone-in-cone to shearing or fracturing commonly fail to make the case against

507 superimposed deformation onto pre-existing cone-in-cone; the relatively pristine preservation of the

508 Jordan sample shows that cone-in-cone can form without invoking a stage of deformation that follows

509 the original precipitation.

510 Acknowledgements. This work has been funded by Shell International Exploration and Production

511 B.V. We are grateful to M. Ali Hussein and M. Alqudah for pointing out the cone-in-cone sample to

512 us, and for discussion of its form and origin. We thank J. Huggett, A. Dickson, S. van den Boorn, O.

513 Podlaha, M. Gross, R. Pierpont, and M. Claps for helpful discussion. We thank J. Wells for sample

514 preparation and O. Green and N. Charnley for assistance with microscopes. We thank J. Marshall for

515 an insightful review, H. Løseth and J. Hendry for helpful reviews of a previous version of this

516 manuscript, and M. Allen for seeing this manuscript through the review process.

517 Declaration of Interest. This work has been funded by Shell International Exploration and Production 518 B.V. 
519 References

520 ÁBALOS, B. \& ElORZA, J. 2011. Latest Cretaceous cone-in-cone structures and soft-sediment

521 deformation (Basque-Cantabrian Basin, north Spain): A record of deep-marine paleoseismicity?

522 Geological Society of America Bulletin 123 (3-4), 427-38.

523 ABED, A.M. \& AMIREH, B.S. 1983. Petrography and geochemistry of some Jordanian oil shales from

524 north Jordan. Journal of Petroleum Geology 5 (3), 261-74.

525 ABED, A.M. \& AL-AGHA, M.R. 1989. Petrography, geochemistry and origin of the NW Jordan

526 phosphorites. Journal of the Geological Society 146, 499-506.

527 AbU-JABer, N.S., Kimberley, M.M. \& CAVAroc, V.V. 1989. Mesozoic-Paleogene basin

528 development within the eastern Mediterranean borderland. Journal of Petroleum Geology 12 (4),

$529 \quad 419-36$.

530 Ali Hussein, M., Alqudah, M., Podlaha, O.G., van den Boorn, S., Kolonic, S. \&

531 MUTTERLOSE, J. 2014a. Ichnofabrics of Eocene oil shales from central Jordan and their use for

532 paleoenvironmental reconstructions. GeoArabia 19 (1), 145-60.

533 Ali Hussein, M., AlQudah, M., van Den Boorn, S., Kolonic, S., Podlaha, O.G. \&

534 MUTTERLOSE, J. 2014b. Eocene oil shales from Jordan - their petrography, carbon and oxygen stable

535 isotopes. GeoArabia 19 (3), 139-62.

536 Alqudah, M., Ali Hussein, M., Podlaha, O.G., VAn den Boorn, S., Kolonic, S. \&

537 MutTERLOSE, J. 2014. Calcareous nannofossil biostratigraphy of Eocene oil shales from central

538 Jordan. GeoArabia 19 (1), 117-40.

539 AsO, E., GISBERT, T.J. \& GARCÉS, B.V. 1992. Type septaria-cone in cone nodules in the Stephano-

540 Permian of the Catalan Pyrenees. Carbonates and Evaporites 7 (2), 132-9.

541 Aydin, A. \& DeGrAFF, J.M. 1988. Evolution of polygonal fracture patterns in lava flows. Science

$542 \quad 239(4839), 471-6$. 
543 Bellamy, J. 1977. Subsurface expansion megapolygons un Upper Jurassic dolostone (Kimmeridge,

544 UK). Journal of Sedimentary Petrology 47, 973-8.

545 BENDER, F. 1974. Geology of Jordan. Berlin: Gebrüder Borntraeger, 196 pp.

546 BEYDOUN, Z.R., FUTYAN, A.R.I. \& JAWZI, A.H. 1994. Jordan revisited: hydrocarbon habitats and

547 potential. Journal of Petroleum Geology 17 (2), 177-94.

548 Bons, P.D., ElBURG, M.A. \& GoMEZ-RIVAs, E. 2012. A review of the formation of tectonic veins

549 and their microstructures. Journal of Structural Geology 43, 33-62.

550 CARTWRIGHT, J. 2011. Diagenetically induced shear failure of fine-grained sediments and

551 development of polygonal fault systems. Marine and Petroleum Geology 28, 1593-610.

552 CobBold, P.R. \& RodRigues, N. 2007. Seepage forces, important factors in the formation of

553 horizontal hydraulic fractures and bedding-parallel fibrous veins ('beef' and 'cone-in-cone').

554 Geofluids 7, 313-22.

555 CobBold, P.R., ZANella, A., Rodrigues, N. \& LøSETH, H. 2013. Bedding parallel fibrous veins

556 (beef and con-in-cone): Worldwide occurrence and possible significance in terms of fluid

557 overpressure, hydrocarbon generation and mineralization. Marine and Petroleum Geology 43, 1-20.

558 COLE, G.A.J. 1893. On some examples of cone-in-cone structure. Mineralogical Magazine 10, 13655941.

560 De Yoreo, J.J. \& VeKILOV, P.G. 2003. Principles of crystal nucleation and growth. Reviews in 561 Mineralogy and Geochemistry 54, 57-93.

562 DuRrance, E.M. 1965. Cone-in-cone structures: a new investigation. Proceedings of the Geologists' 563 Association 76 (1), 83-9.

564 EyAL, Y. \& ReCHES, Z. 1983. Tectonic analysis of the Dead Sea rift region since the late-Cretaceous 565 based on mesostructures. Tectonics 2 (2), 167-85. 
566 FRANKS, P.C. 1969. Nature, origin, and significance of cone-in-cone structures in the Kiowa

567 Formation (early Cretaceous), north-central Kansas. Journal of Sedimentary Petrology 39 (4), $1438-$

56854.

569 GiLman, R.A. \& MetzGer, W.J. 1967. Cone-in-cone concretions from western New York. Journal of

570 Sedimentary Petrology 37 (1), 87-95.

571 GReSLEY, W.S. 1894. Cone-in-cone: how it occurs in the 'Devonian' Series in Pennsylvania, U.S.A., 572 with further details of its structure, varieties, etc. Quarterly Journal of the Geological Society 50, $573 \quad 731-9$

574 HENDRY, J.P. 2002. Geochemical trends and paleohydrological significance of shallow burial calcite 575 and ankerite cements in Middle Jurassic strata on the East Midlands Shelf (onshore UK). Sedimentary 576 Geology 151, 149-76.

577 HiLgERS, C. \& URAI, J.L. 2005. On the arrangement of solid inclusions in fibrous veins and the role of 578 the crack-seal mechanism. Journal of Structural Geology 27, 481-94.

579 Hillier, R.D. \& Cosgrove, J.W. 2002. Core and seismic observations of overpressure-related 580 deformation within Eocene sediments of the Outer Moray Firth, UKCS. Petroleum Geoscience 8, $581 \quad 141-9$

582 Hornig, T., Sokolov, I.M. \& Blumen, A. 1996. Patterns and scaling in surface fragmentation 583 processes. Physical Review E 54 (4), 4293-8.

584 IsRaElson, C., HallidAy, A.N. \& BUCHARDT, B. 1996. U-Pb dating of calcite concretions from 585 Cambrian black shales and the Phanerozoic time scale. Earth and Planetary Science Letters 141, 1535869.

587 KINDLE, E.M. 1917. Factors affecting the development of mud-cracks. Journal of Geology 25 (2), $588 \quad 135-44$ 
589 KOLOKOL'TSEV, V.G. 2002. The cone-in-cone structure and its origin. Lithology and Mineral

$590 \quad$ Resources 37 (6), 523-35.

591 Kowal-LinKA, M. 2010. Origin of cone-in-cone calcite veins during calcitization of dolomites and 592 their subsequent diagenesis: A case study from the Gogolin Formation (Middle Triassic) SW Poland. 593 Sedimentary Geology 224, 54-64.

594 Le Breton, E., Cobbold, P.R. \& Zanella, A. 2013. Cenozoic reactivation of the Great Glen Fault, 595 Scotland: additional evidence and possible causes. Journal of the Geological Society, London 170, $596 \quad 403-15$.

597 LÜNING, S. \& KUSS, J. 2014. Petroleum geology of Jordan. In Petroleum systems of the Tethyan 598 region (eds L. Marlow, C. Kendall \& L. Yose), pp. 217-39. AAPG Memoir 106.

599 MAHER, H.D., JR, OGATA, K. \& BRAATHEN, A. 2016. Cone-in-cone and beef mineralization 600 associated with the Triassic growth basin faulting and shallow shale diagenesis, Edgeøya, Svalbard. 601 Geological Magazine, available on CJO2016. doi: 10.1017/S0016756815000886.

602 MARSHALL, J.D. 1982. Isotopic composition of displacive fibrous calcite veins: reversals in pore603 water composition trends during burial diagenesis. Journal of Sedimentary Petrology 52 (2), 615-30. 604 MCBRide, E.F., PiCARD, M.D. \& Milliken, K.L. 2003. Calcite-cemented concretions in Cretaceous 605 sandstone, Wyoming and Utah, U.S.A. Journal of Sedimentary Research 73 (3), 462-83.

606 MERINO, E. \& CANALS, A. 2011. Self-accelerating dolomite-for-calcite replacement: self-organized 607 dynamics of burial dolomitization and associated mineralization. American Journal of Science 311, $608 \quad 573-607$.

609 Moss, S. \& TUCKER, M.E. 1995. Diagenesis of Barremian-Aptian platform carbonates (the Urgonian 610 Limestone Formation of SE France): near-surface and shallow-burial diagenesis. Sedimentology 42 , $611 \quad 853-74$. 
612 OlsON, J.E. \& POLLARD, D.D. 1991. The initiation and growth of en échelon veins. Journal of

613 Structural Geology 13, 595-608.

614 Parnell, J., Blamey, N.J.F., Costanzo, A., Feely, M. \& BoyCe, A.J. 2013. Preservation of

615 Mesoproterozoic age deep burial fluid signatures, NW Scotland. Marine and Petroleum Geology 55,

$616 \quad 275-81$.

617 Powell, J.H. \& MoH'D, B.K. 2011. Evolution of Cretaceous to Eocene alluvial and carbonate

618 platform sequences in central and south Jordan. GeoArabia 16 (4), 29-82.

619 PUfAHL, P.K., GRIMM, K.A., ABED, A.M. \& SADAQAH, R.M.Y. 2003. Upper Cretaceous (Campanian)

620 phosphorites in Jordan: implications for the formation of a south Tethyan phosphorite giant.

621 Sedimentary Geology 161, 175-205.

622 Richardson, W. A. 1923. Part III: Petrology. In LANG, W. D., SPATH, L. F. \& Richardson, W. A.,

623 Shales-with-'Beef,' a sequence in the Lower Lias of the Dorset Coast. Quarterly Journal of the

624 Geological Society 79, 47-99.

625 SELLÉS-MARTíneZ, J. 1994. New insights in the origin of cone-in-cone structures. Carbonates and

$626 \quad$ Evaporites 9 (2), 172-86.

627 SELLÉS-MARTínEZ, J. 1996. Concretion morphology, classification and genesis. Earth Science

628 Reviews 41, 177-210.

629 Shearman, D.J., Mossop, G., Dunsmore, H. \& Martin, M. 1972. Origin of gypsum veins by

630 hydraulic fracture. Transactions of the Institute of Mining and Metallurgy 181, B149-55.

631 TARR, W.A. 1922. Cone-in-cone. American Journal of Science Series 5, 4, 199-213.

632 TARR, W.A. 1932. Cone-in-cone. In Treatise on sedimentation, $2^{\text {nd }}$ ed. (ed W.H. Twinhofel), pp. 716-

633 33. Baltimore: Williams and Wilkins Co.

634 TUCKER, M.E. \& WRIGHT, P.W. 1990. Carbonate Sedimentology. Oxford: Blackwell, 482 pp. 
635 WoodLAND, B.G. 1964. The nature and origin of cone-in-cone structure. Fieldiana: Geology 13, $636 \quad 187-305$.

\section{$637 \quad$ Figure captions}

638 Figure 1. (Colour online) Hypotheses for the timing of cones. Cone-in-cone shown growing 639 downward to match the sample under investigation. For primary cone-in-cone, calcite is deposited 640 with its conic shape, generally displacing host-sediment but including some host sediment, which 641 demarcates the cones, as the structure grows. For secondary cone-in-cone, calcite grows in a tabular 642 or elliptical form, displacing host-sediment without including conical strands of sediment. Cones form 643 in a post-precipitation stage, as host material is injected into the calcite along fractures. Horizontal 644 lines in both cases represent growth bands, not fibres, which would be subvertical and are omitted for 645 clarity. Bands are arbitrarily coloured/shaded to illustrate coeval cement. Note offset across bands is 646 coeval with precipitation for primary cone-in-cone; offset is related to shear fracturing for secondary 647 cone-in-cone.

648 Figure 2. (a) Location of the core site. Flood basalts and major faults from Beydoun, Futyan \& Jawzi, 649 (1994), Ali Hussein et al. (2014b) and Lüning \& Kuss (2014). (b) Simplified stratigraphy of the Belqa 650 Group, after Powell \& Moh'd (2011), containing the cored interval. The cone-in-cone layer is within 651 the Muwaqqar Formation. (c) Schematic burial history curve for the cone-in-cone sample studied.

652 Figure 3. (Colour online) Cone-in-cone structure from the Muwaqqar Formation, Jordan. (a) Core 653 photo. (b) Thin section scan. White dashed lines mark sub-vertical fractures, roughly $100 \mu \mathrm{m}$ wide. 654 Layer-parallel bands are more transparent at this scale because they contain less host sediment and 655 more calcite. Locations of petrographic images in Figures 6, 7, 9, and 13 indicated. Locations of 656 Figures 5 and 10 are approximate; those figures were made from an accompanying SEM-polished thin 657 section. Black dashed line shows transect across which horizontal scanlines were drawn; see Figure 8.

658 Figure 4. (Colour online) Schematic of cone-in-cone, including terms used in this study. Crystals are 659 variously shaded to resemble the extinction patterns seen using cross-polarised light. Crystals are 660 commonly demarcated by thinner host-rock strands than the one illustrated; these smaller strands are 
661 omitted for clarity. Note spatial density of rhombs within cones is proportional to the amount of host

662 material in the cones, and therefore is lowest within the band (c.f. Fig. 7).

663 Figure 5. SEM-CL image of dolomite rhombs within host-rock strand. See Figure 3 for approximate 664 location. Note most dolomite rhombs have concentric zoning. Rough edges are likely an artefact of 665 polishing, given the highly luminescent polishing grit entrained within the matrix and around the 666 rhombs.

667 Figure 6. (Colour online) Cone-in-cone and host-rock strands. See Figure 3 for locations. (a) Plane668 polarised light image of cone-in-cone with regions of sub-microscopic calcite crystals. (b)

669 Interpretation of (a). The sub-microscopic calcite crystals near the top of the field of view are likely

670 finer-scale cones, on the basis of intervening host-rock strands showing similar orientations to those in

671 resolvable cone-in-cone. Lower, the isolated calcite bodies are composed in part of resolvable cones,

672 yet tend to extend laterally into disk-shapes (arrowed). (c) Host-rock strand among calcite cones; note

673 dolomite rhombs and foraminifera test (arrowed). (d) Map-view of sample showing discontinuous, 674 annular form of host-rock strands.

675 Figure 7. (Colour online) Petrographic images of cone-in-cone. See locations in Figure 3. (a)

676 Microscopic cones (transparent) separated by host-rock strands (opaque). Plane-polarised light. (b)

677 Same as (a), cross-polarised light. Note crystals at coarser scale than cones. Dispersed white spots are

678 dolomite rhombs. (c) Microscopic cones forming a macroscopic cone separated from neighbouring

679 crystals by thicker host-rocks strands. Plane-polarised light. (d) Same as (c), cross-polarised light. In

680 (b) and (d), note rhomb density coincides spatially with host-rock strand density, both being lowest

681 within the band.

682 Figure 8. Abundance of rhombs and siliceous matrix, within cone-in-cone and host-rock. (a) Variation 683 across bands within cone-in-cone; see approximate location of transect in Figure 3. (b) Crossplot of 684 the same data in (a) including host-rock measurements. Best-fit linear extrapolation from cone-in685 cone measurements intersects the host-rock measurements, meaning that the rhomb:matrix ratio does 686 not systematically vary from $\sim 0.7$, throughout the core sample. 
687 Figure 9. (Colour online) Corrugations. See locations in Figure 3. (a) Plane-polarised light image of

688 host-rock strand having consistently corrugated upper surface and smooth lower surface. (b)

689 Interpretation of growth sequence of (a). Arbitrarily coloured/shaded lines follow the inconsistently

690 corrugated, downward-growing bottom surface of the cone-in-cone structure. Growth lines in left-side

691 cone labelled sequentially. Lower cones halt the growth of upper cones; see text for discussion. (c)

692 Cones at the lower surface of cone-in-cone. (d) Interpretation of (c), highlighting inconsistent

693 corrugation along the bottom surface and consistent corrugation of the smaller-scale cones that make

694 up the larger cones.

695 Figure 10. SEM images of cone-in-cone. See Figure 3 for approximate location. (a) Backscattered

696 electron image showing distribution of dolomite crystals. Ca, calcite; Dol, dolomite. (b) CL image.

697 Dolomite is zoned. R, rhomb; DC, dolomite crystal (some include rhombs). Rhombs have the

698 characteristic size and concentric zoning pattern of host-rock rhombs (Fig. 5); matrix mud is included

699 around rhombs. Dolomite crystals that contain rhombs also have non-concentrically zoned dolomite

700 extending downward from the rhomb. (c) EDS image. HR, host-rock strand. (d) superposition of (b)

701 and (c) to highlight the zoning within dolomite and relationships between dolomite and calcite.

702 Dolomite crystals share vertical boundaries with fibrous calcite. Where rhombs are overgrown by

703 authigenic dolomite in a crystal, the two are in optical continuity (inset-yellow lines mark optically

704 continuous crystals), and rhombs are at the top of the crystal. This suggests that the overgrowths grew

705 downward from the rhombs, terminating against calcite fibres as the cone-in-cone grew. Dolomite

706 crystals without rhombs may overgrow rhombs that are out of the thin section plane, or they may be

707 purely authigenic crystals. (e) SEM-CL-EDS image, combined as in (d), of another example of a

708 dolomite crystal including a concentrically zoned rhomb at its upper end.

709 Figure 11. (Colour online) Timing hypotheses for (top) calcite, cones, and dolomite rhombs; (bottom)

710 dolomite crystals amid calcite. At top, cone-in-cone may be primary, originating with the calcite

711 precipitation, or secondary, post-dating the calcite. Dolomite rhombs may pre- or post-date calcite

712 (former are detrital or early-authigenic; latter are late-authigenic). The final arrangement is identical

713 in each case. At bottom, stripes represent calcite crystals, which are vertical or follow host-rock 
714 strands (Figs. 7, 10). If dolomite crystals post-date calcite, then they grew by replacing calcite, and so

715 should extend outward from rhombs in all directions, or at least extend upward as easily as

716 downward. The observed arrangement (Fig. 10) shows dolomite crystals extending downward from

717 rhombs and not upward. This suggests that the rhombs were already present when the calcite formed,

718 and that the dolomite crystals co-precipitated with calcite.

719 Figure 12. Schematic of growth of cone-in-cone. (a) Two large-scale cones meet at a host-rock strand

720 with consistently corrugated upper side, formed by the halting of the upper cone against the lower

721 cone. This halting happens because there is not enough room for medium-scale cones within the upper

722 cone to grow against the lower cone. The dashed blue line represents space which cannot be filled by

723 calcite cones; consequently the next row of medium-scale cones within the upper large-scale cone will

724 'backstep' to the right. The vertical separation defining 'upper' and 'lower' can be seen in the offset

725 of both the band and the lower large-scale conic surfaces. These bottom surfaces are inconsistently

726 corrugated rows of medium-scale cones. Dolomite rhombs and overgrowths drawn as in Figure 11.

727 The band marks the previous basal surface of the structure. (b) Ensconcement of dolomite rhomb and

728 development of overgrowth. As calcite cones grow downward (time-steps 1 to 5), host-rock rhombs

729 are mostly pressed downward and out of the frame; one rhomb is entrained in the lattice. A dolomite

730 overgrowth grows downward from the rhomb, blocking the growing calcite. At time-step 5, the

731 dolomite crystal has formed a lower euhedral termination and neighbouring calcite crystals continue

732 growing downward in its place. (c) Small-scale cones illustrate how the corrugation of cone-bounding

733 host-rock strands is analogous at smaller scales — see Figure 13.

734 Figure 13. (Colour online) Reconstruction of two interfering, macroscopic cones (Fig. 3). (a) Plane-

735 polarised light image showing the intersection of two large-scale cones. (b-e) Interpretation and

736 reconstruction of (a); (e) shows final state photographed in (a). Host-rock rhombs are pushed

737 downward from growing cones or ensconced within the cone calcite. The higher large-scale cone on

738 right cannot grow laterally into the space occupied by the lower cone on left. The left-side cone, being

739 lower, therefore blocks the growth of the right-side cone, and the boundary between them moves to

740 the right as the cones grow downward. The blocking of the right-side cone produces a consistently 
1

2

3

4

5

6

7

8

9

10

11

12

13

14

15

16

17

18

19

20

21

22

23

24

25

26

27

28

29

30

31

32

33

34

35

36

37

38

39

40

41

42

43

44

45

46

47

48

49

50

51

52

53

54

55

56

57

58

59

60

741 corrugated upper surface to the host-rock strand demarcating the cones. The smooth lower surface of

742 the strand defines the top of the left-side cone. The flat bottom-surface of the cone-in-cone is

743 inconsistently corrugated throughout the growth process. Note consistent corrugation of strands

744 between smaller-scale cones, suggesting that the same blocking process occurs at smaller scales. 
Primary cone-in-cone
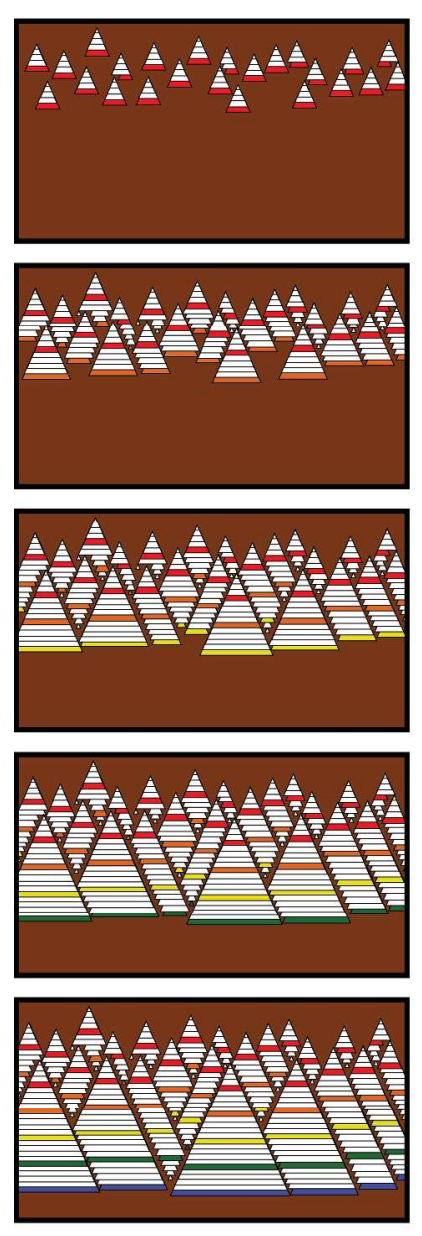

Secondary cone-in-cone

Precipitation phase
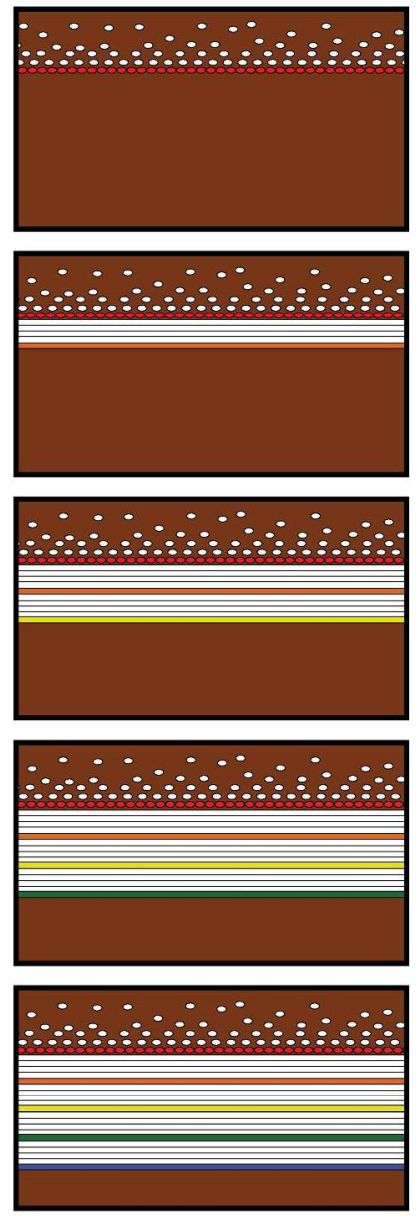

Fracturing phase

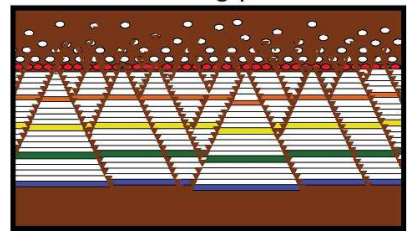

Figure 1. (Colour online) Hypotheses for the timing of cones. Cone-in-cone shown growing downward to match the sample under investigation. For primary cone-in-cone, calcite is deposited with its conic shape, generally displacing host-sediment but including some host sediment, which demarcates the cones, as the structure grows. For secondary cone-in-cone, calcite grows in a tabular or elliptical form, displacing hostsediment without including conical strands of sediment. Cones form in a post-precipitation stage, as host material is injected into the calcite along fractures. Horizontal lines in both cases represent growth bands, not fibres, which would be subvertical and are omitted for clarity. Bands are arbitrarily coloured/shaded to illustrate coeval cement. Note offset across bands is coeval with precipitation for primary cone-in-cone; offset is related to shear fracturing for secondary cone-in-cone. 

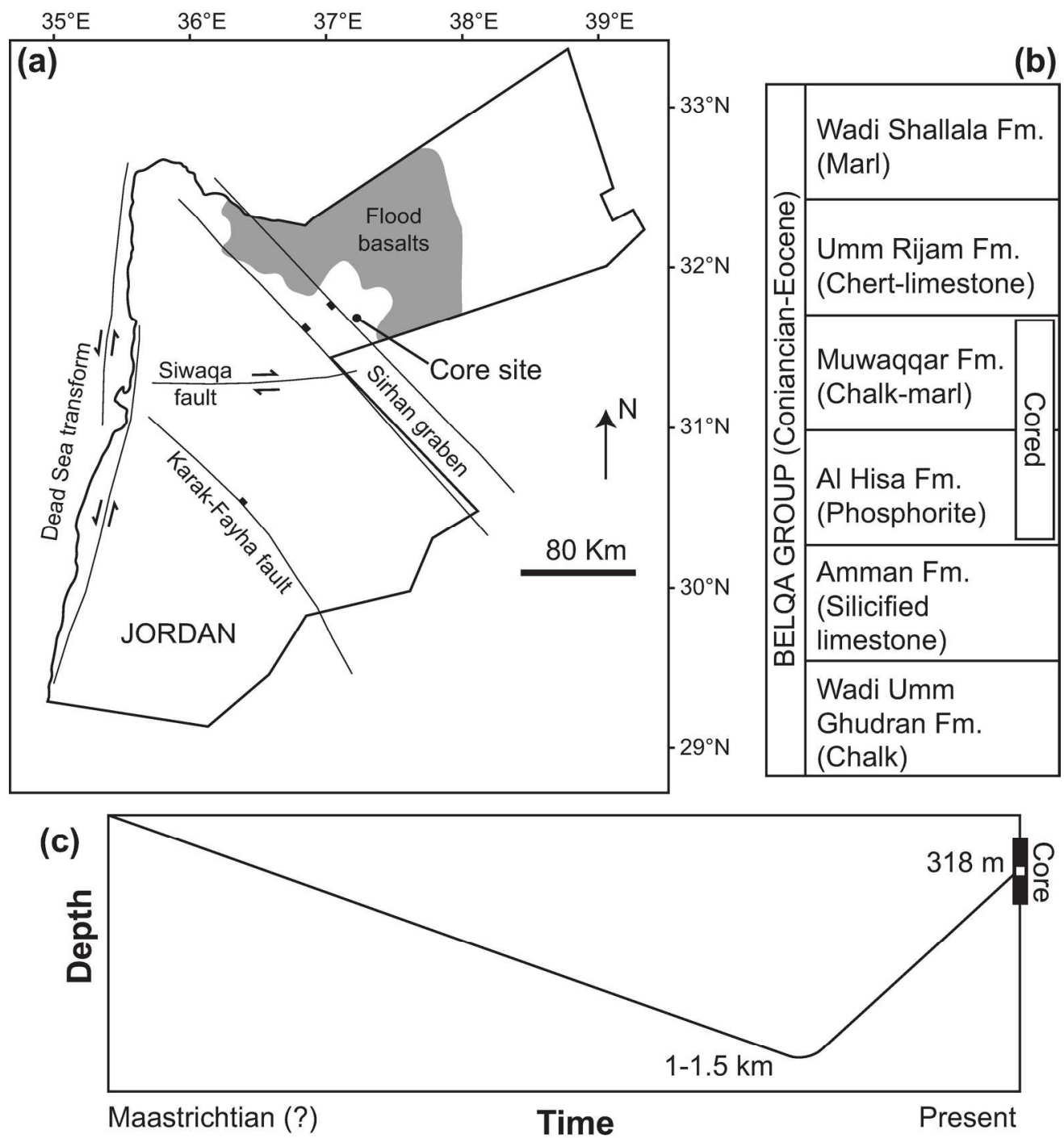

Figure 2. (a) Location of the core site. Flood basalts and major faults from Beydoun, Futyan \& Jawzi, (1994), Ali Hussein et al. (2014b) and Lüning \& Kuss (2014). (b) Simplified stratigraphy of the Belqa Group, after Powell \& Moh'd (2011), containing the cored interval. The cone-in-cone layer is within the Muwaqqar Formation. (c) Schematic burial history curve for the cone-in-cone sample studied.

$$
180 \times 195 \mathrm{~mm}(300 \times 300 \text { DPI) }
$$



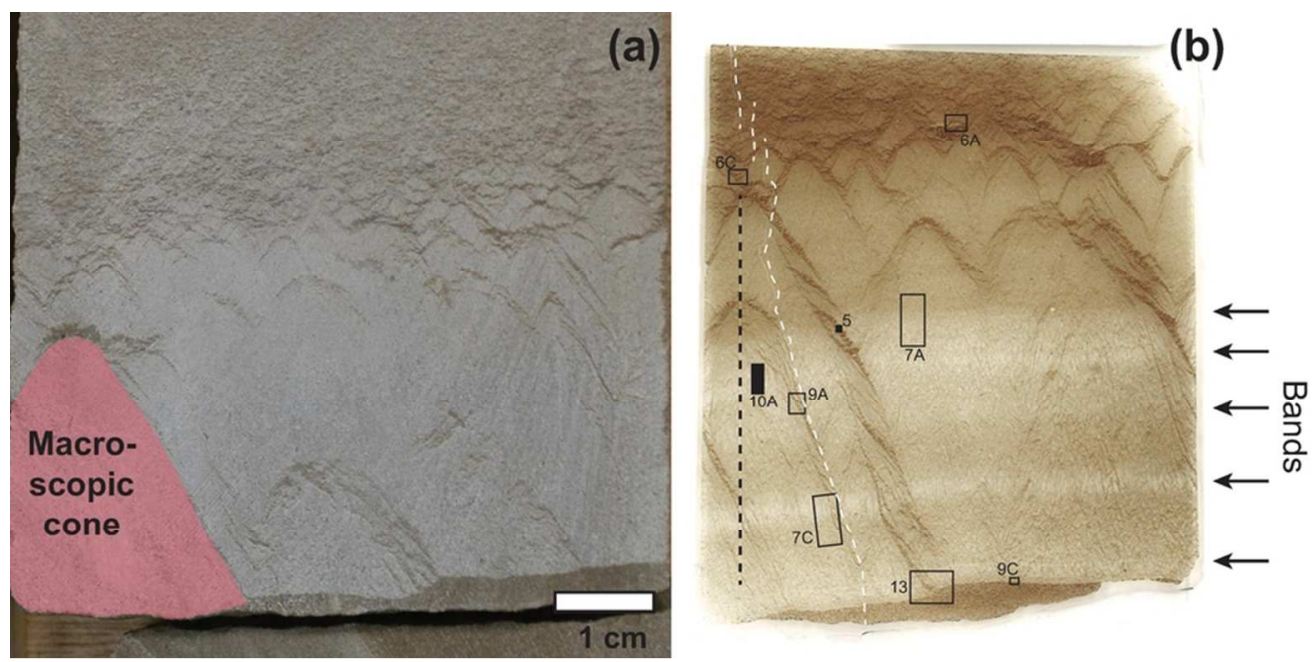

Figure 3. (Colour online) Cone-in-cone structure from the Muwaqqar Formation, Jordan. (a) Core photo. (b) Thin section scan. White dashed lines mark sub-vertical fractures, roughly $100 \mu \mathrm{m}$ wide. Layer-parallel bands are more transparent at this scale because they contain less host sediment and more calcite.

Locations of petrographic images in Figures $6,7,9$, and 13 indicated. Locations of Figures 5 and 10 are approximate; those figures were made from an accompanying SEM-polished thin section. Black dashed line shows transect across which horizontal scanlines were drawn; see Figure 8.

$82 \times 40 \mathrm{~mm}(300 \times 300 \mathrm{DPI})$ 
Figure 4. (Colour online) Schematic of cone-in-cone, including terms used in this study. Crystals are variously shaded to resemble the extinction patterns seen using cross-polarised light. Crystals are commonly demarcated by thinner host-rock strands than the one illustrated; these smaller strands are omitted for clarity. Note spatial density of rhombs within cones is proportional to the amount of host material in the cones, and therefore is lowest within the band (c.f. Fig. 7). 
Figure 5. SEM-CL image of dolomite rhombs within host-rock strand. See Figure 3 for approximate location. Note most dolomite rhombs have concentric zoning. Rough edges are likely an artefact of polishing, given the highly luminescent polishing grit entrained within the matrix and around the rhombs.

\section{$53 \times 35 \mathrm{~mm}(300 \times 300 \mathrm{DPI})$}



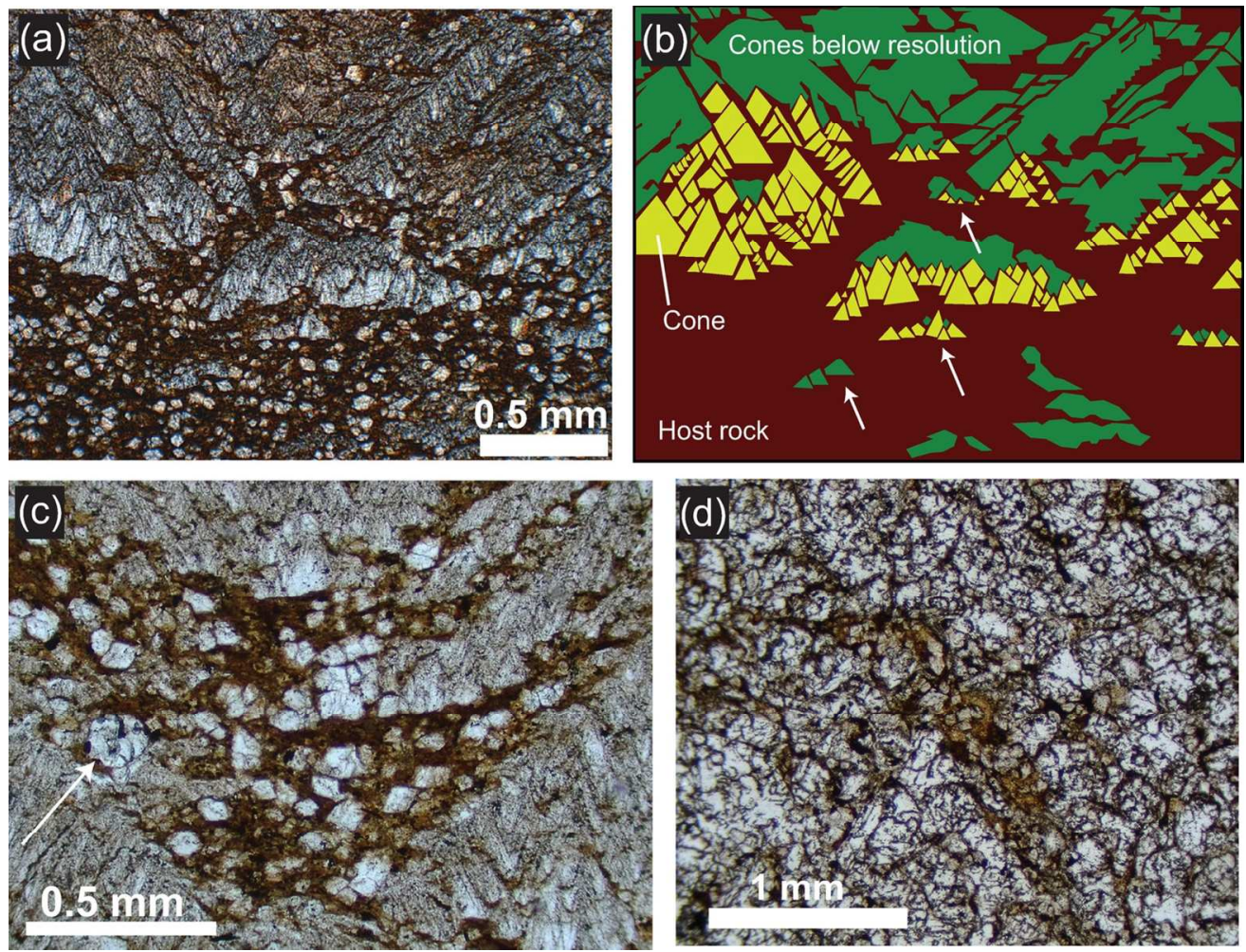

Figure 6. (Colour online) Cone-in-cone and host-rock strands. See Figure 3 for locations. (a) Plane-polarised light image of cone-in-cone with regions of sub-microscopic calcite crystals. (b) Interpretation of (a). The sub-microscopic calcite crystals near the top of the field of view are likely finer-scale cones, on the basis of intervening host-rock strands showing similar orientations to those in resolvable cone-in-cone. Lower, the isolated calcite bodies are composed in part of resolvable cones, yet tend to extend laterally into disk-shapes (arrowed). (c) Host-rock strand among calcite cones; note dolomite rhombs and foraminifera test (arrowed). (d) Map-view of sample showing discontinuous, annular form of host-rock strands. 

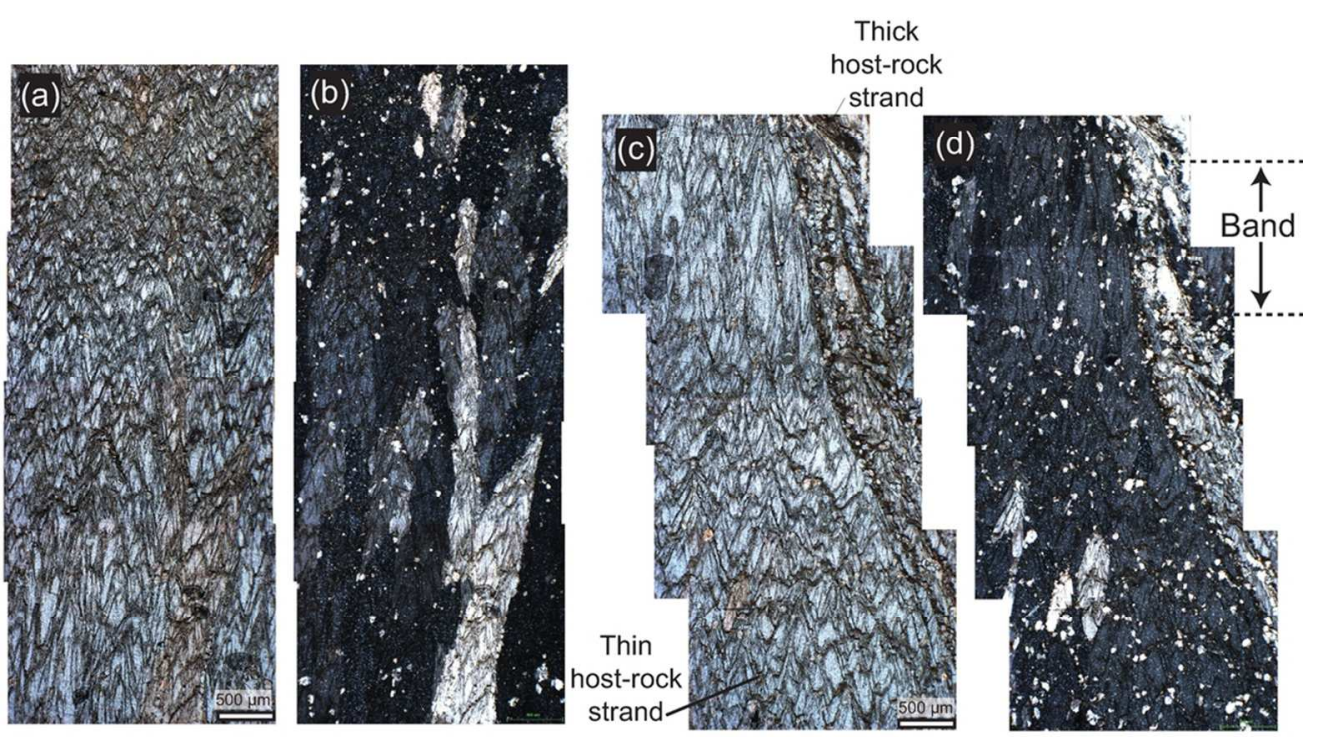

Figure 7. (Colour online) Petrographic images of cone-in-cone. See locations in Figure 3. (a) Microscopic cones (transparent) separated by host-rock strands (opaque). Plane-polarised light. (b) Same as (a), crosspolarised light. Note crystals at coarser scale than cones. Dispersed white spots are dolomite rhombs. (c) Microscopic cones forming a macroscopic cone separated from neighbouring crystals by thicker host-rocks strands. Plane-polarised light. (d) Same as (c), cross-polarised light. In (b) and (d), note rhomb density coincides spatially with host-rock strand density, both being lowest within the band. 
Figure 8. Abundance of rhombs and siliceous matrix, within cone-in-cone and host-rock. (a) Variation across bands within cone-in-cone; see approximate location of transect in Figure 3. (b) Crossplot of the same data in (a) including host-rock measurements. Best-fit linear extrapolation from cone-in-cone measurements intersects the host-rock measurements, meaning that the rhomb:matrix ratio does not systematically vary from $\sim 0.7$, throughout the core sample.

$198 \times 494 \mathrm{~mm}(300 \times 300$ DPI $)$ 

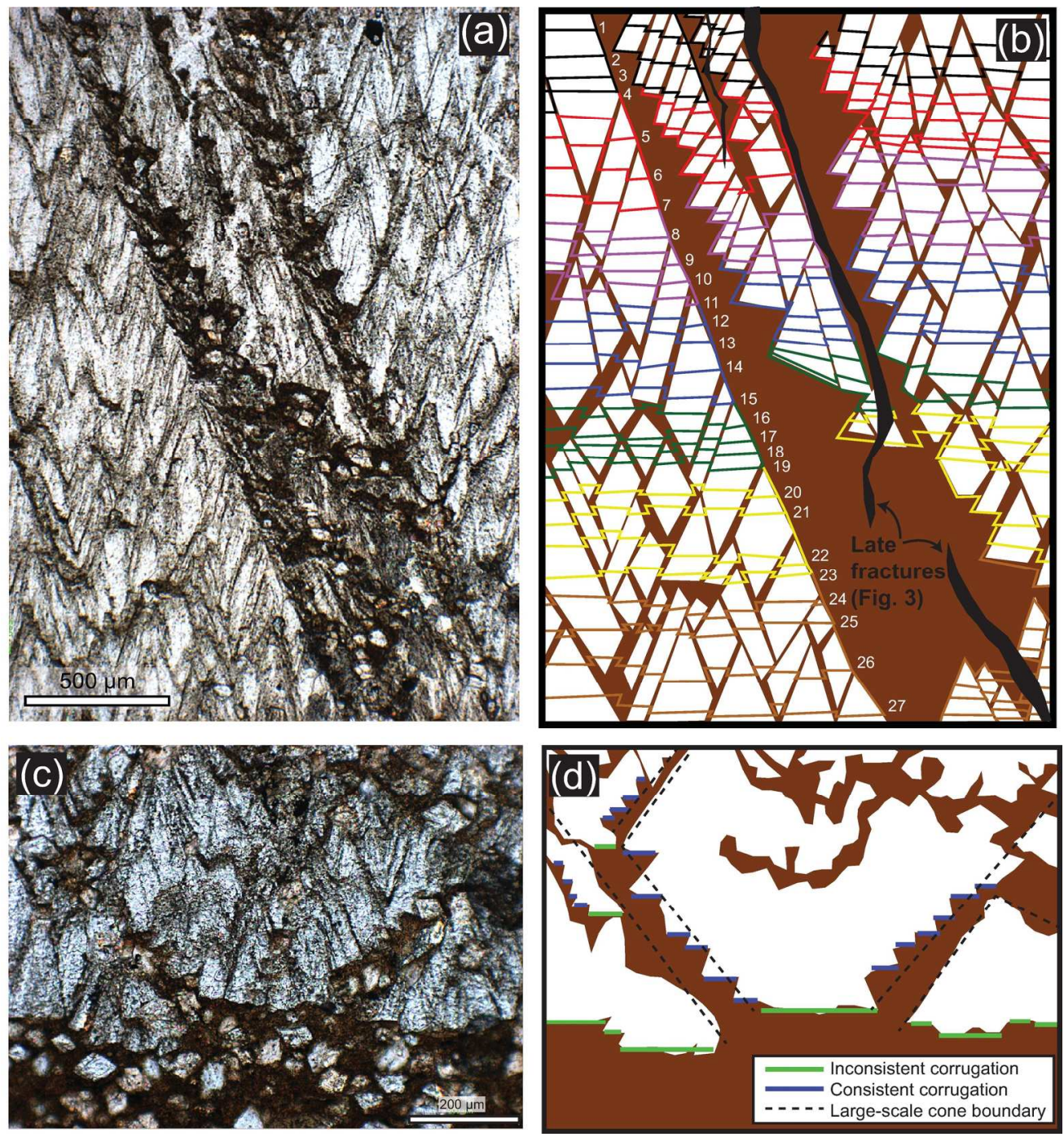

Figure 9. (Colour online) Corrugations. See locations in Figure 3. (a) Plane-polarised light image of host-rock strand having consistently corrugated upper surface and smooth lower surface. (b) Interpretation of growth sequence of (a). Arbitrarily coloured/shaded lines follow the inconsistently corrugated, downward-growing bottom surface of the cone-in-cone structure. Growth lines in left-side cone labelled sequentially. Lower

cones halt the growth of upper cones; see text for discussion. (c) Cones at the lower surface of cone-incone. (d) Interpretation of (c), highlighting inconsistent corrugation along the bottom surface and consistent corrugation of the smaller-scale cones that make up the larger cones. 

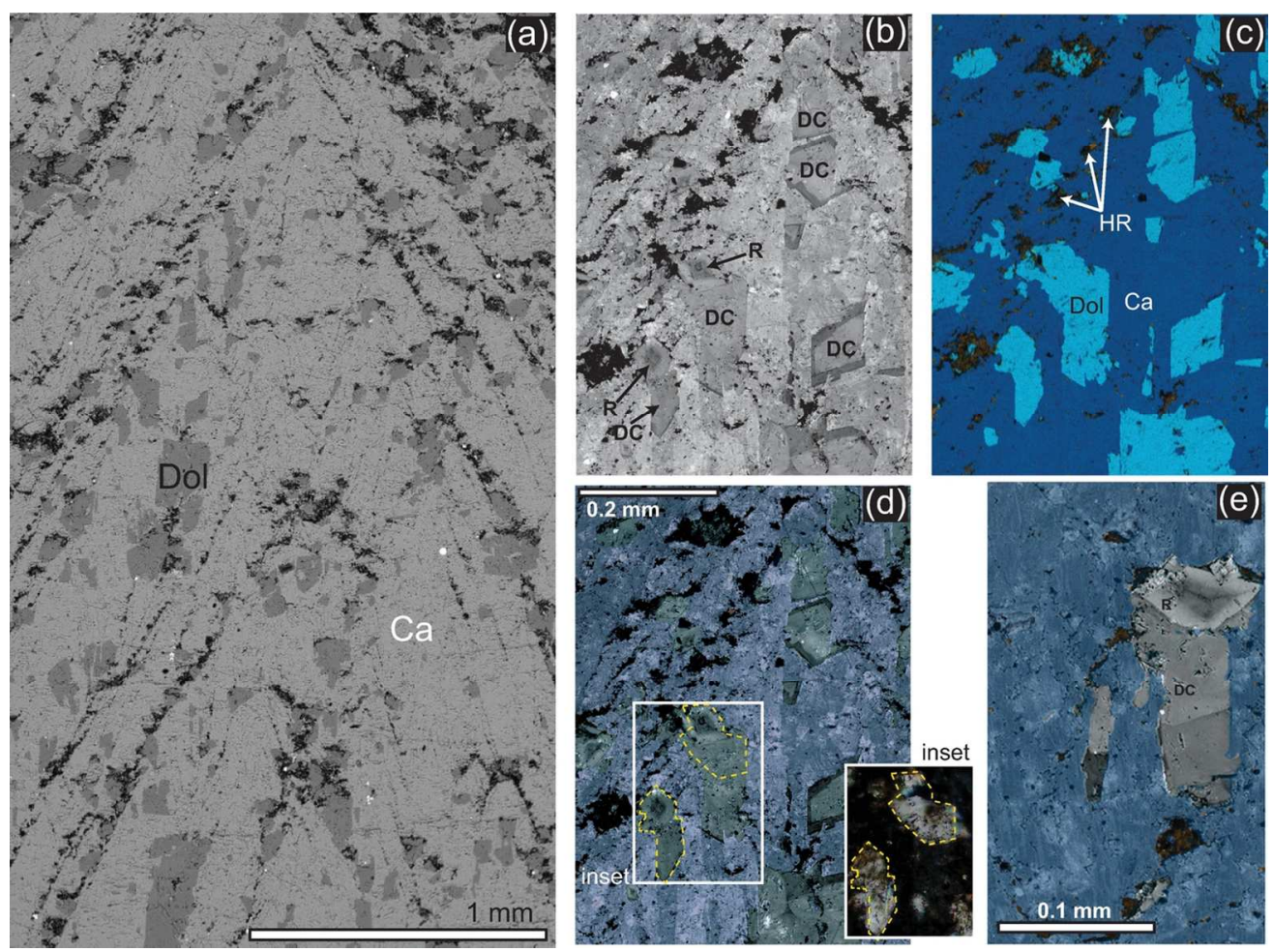

Figure 10. SEM images of cone-in-cone. See Figure 3 for approximate location. (a) Backscattered electron image showing distribution of dolomite crystals. Ca, calcite; Dol, dolomite. (b) CL image. Dolomite is zoned. $\mathrm{R}$, rhomb; DC, dolomite crystal (some include rhombs). Rhombs have the characteristic size and concentric zoning pattern of host-rock rhombs (Fig. 5); matrix mud is included around rhombs. Dolomite crystals that contain rhombs also have non-concentrically zoned dolomite extending downward from the rhomb. (c) EDS image. HR, host-rock strand. (d) superposition of (b) and (c) to highlight the zoning within dolomite and relationships between dolomite and calcite. Dolomite crystals share vertical boundaries with fibrous calcite. Where rhombs are overgrown by authigenic dolomite in a crystal, the two are in optical continuity (insetyellow lines mark optically continuous crystals), and rhombs are at the top of the crystal. This suggests that the overgrowths grew downward from the rhombs, terminating against calcite fibres as the cone-in-cone grew. Dolomite crystals without rhombs may overgrow rhombs that are out of the thin section plane, or they may be purely authigenic crystals. (e) SEM-CL-EDS image, combined as in (d), of another example of a dolomite crystal including a concentrically zoned rhomb at its upper end. 
Primary cone-in-cone
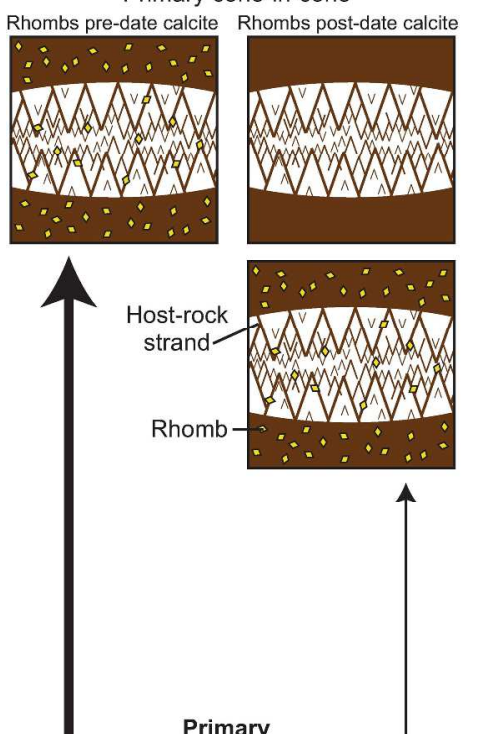

Secondary cone-in-cone

Rhombs pre-date calcite Rhombs post-date calcite
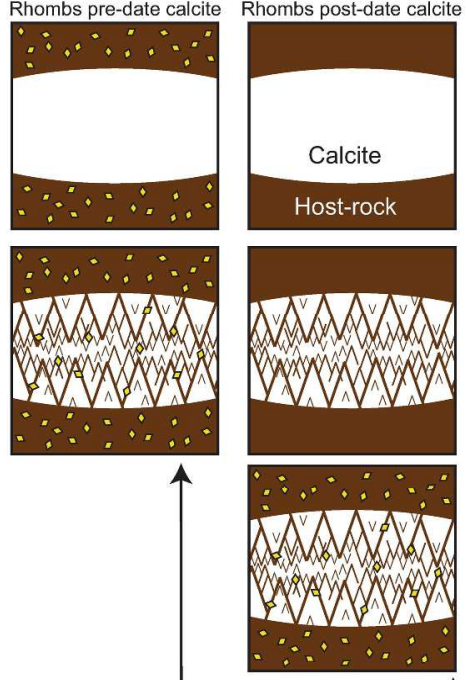

cone-in-cone

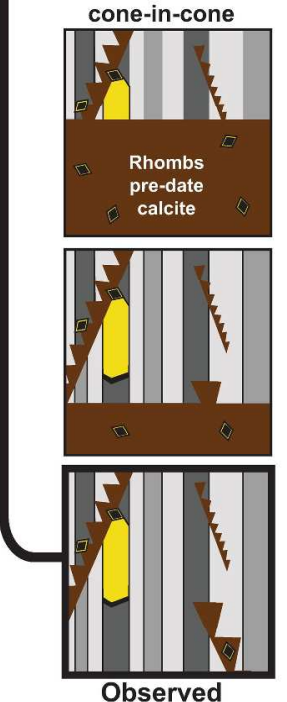

Observed

Dolomite growing with calcite

-From rhomb, downward
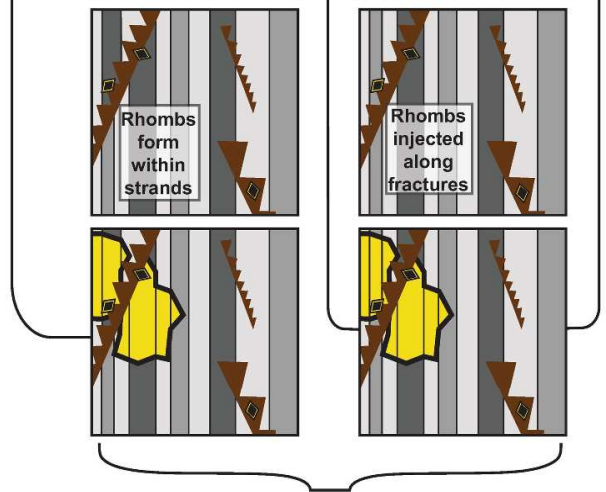

Dolomite replacing calcite -From rhomb, outward

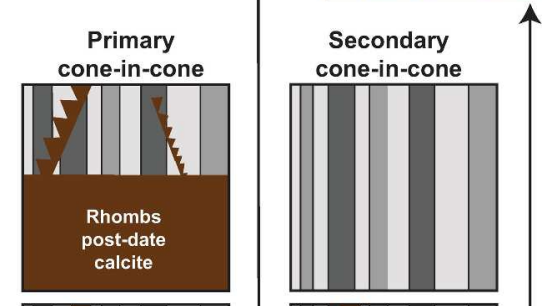

Figure 11. (Colour online) Timing hypotheses for (top) calcite, cones, and dolomite rhombs; (bottom) dolomite crystals amid calcite. At top, cone-in-cone may be primary, originating with the calcite precipitation, or secondary, post-dating the calcite. Dolomite rhombs may pre- or post-date calcite (former are detrital or early-authigenic; latter are late-authigenic). The final arrangement is identical in each case. At bottom, stripes represent calcite crystals, which are vertical or follow host-rock strands (Figs. 7, 10). If dolomite crystals post-date calcite, then they grew by replacing calcite, and so should extend outward from rhombs in all directions, or at least extend upward as easily as downward. The observed arrangement (Fig.

10) shows dolomite crystals extending downward from rhombs and not upward. This suggests that the rhombs were already present when the calcite formed, and that the dolomite crystals co-precipitated with calcite. 
1

2

3

4

5

6

7

8

9

10

11

12

13

14

15

16

17

18

19

20

21

22

23

24

25

26

27

28

29

30

34

35

36

37

38

39

40

41

42

43

44

45

46

47

48

49

50

51

52

53

54

55

56

57

58

59

60 \\ Page 43 of 44}

Proof For Review

(1)

.

.

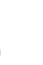

(n)

(1)

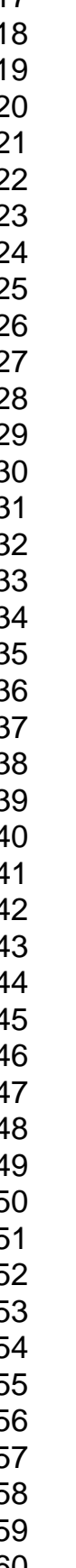

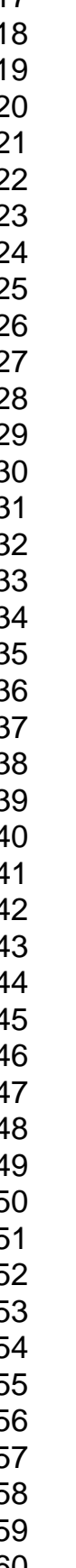

Proof For Review

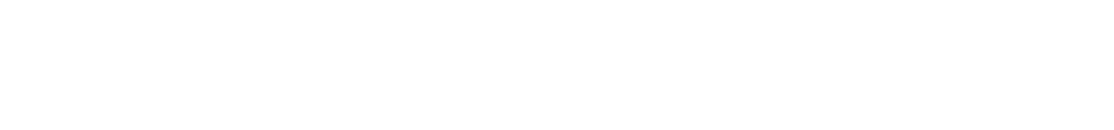

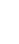



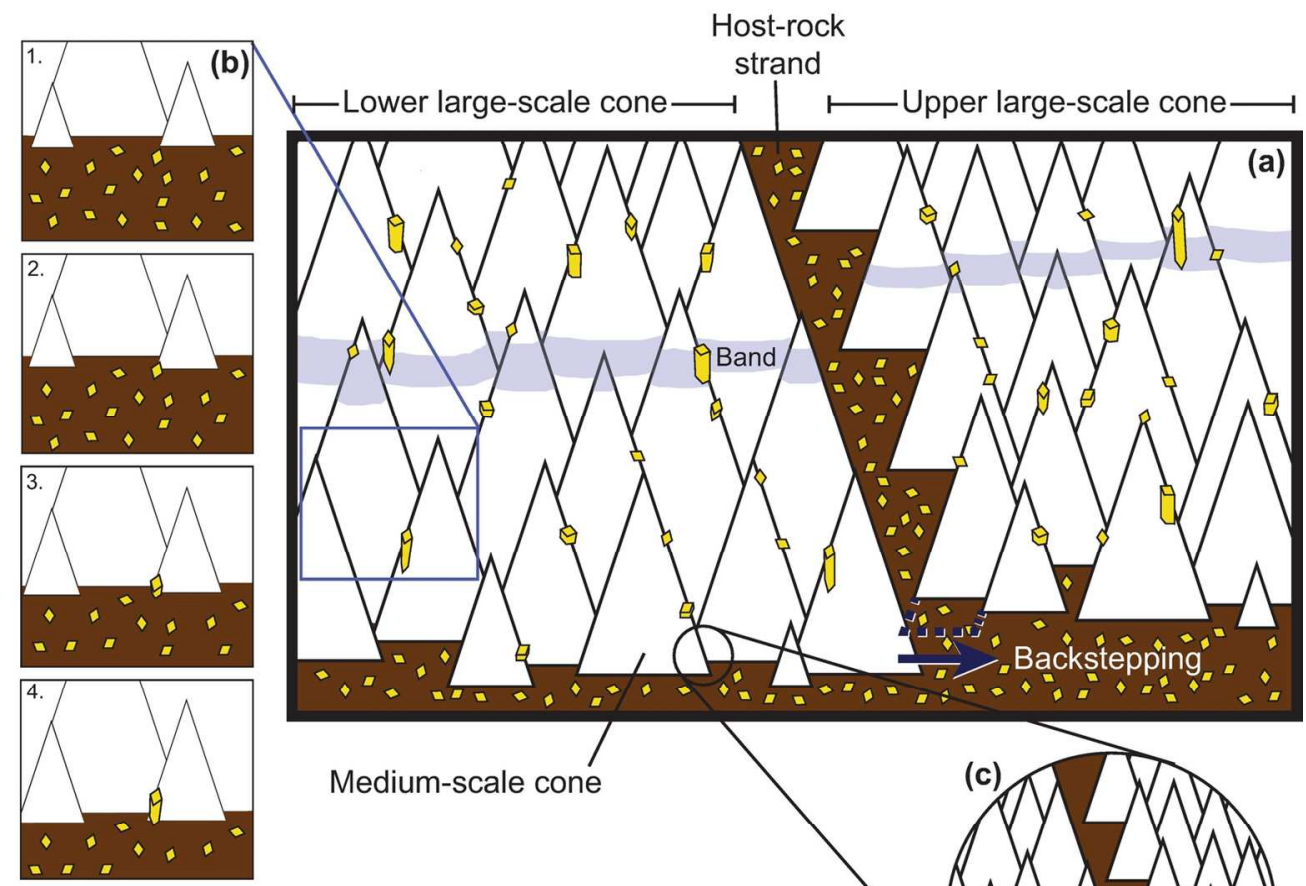

Medium-scale cone
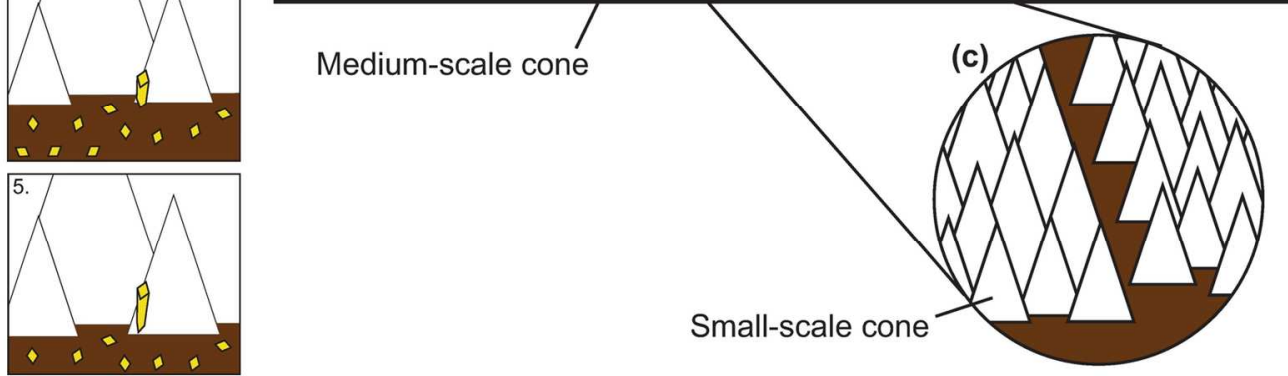

Figure 12. Schematic of growth of cone-in-cone. (a) Two large-scale cones meet at a host-rock strand with consistently corrugated upper side, formed by the halting of the upper cone against the lower cone. This halting happens because there is not enough room for medium-scale cones within the upper cone to grow against the lower cone. The dashed blue line represents space which cannot be filled by calcite cones; consequently the next row of medium-scale cones within the upper large-scale cone will 'backstep' to the right. The vertical separation defining 'upper' and 'lower' can be seen in the offset of both the band and the lower large-scale conic surfaces. These bottom surfaces are inconsistently corrugated rows of medium-scale cones. Dolomite rhombs and overgrowths drawn as in Figure 11. The band marks the previous basal surface of the structure. (b) Ensconcement of dolomite rhomb and development of overgrowth. As calcite cones grow downward (time-steps 1 to 5), host-rock rhombs are mostly pressed downward and out of the frame; one rhomb is entrained in the lattice. A dolomite overgrowth grows downward from the rhomb, blocking the growing calcite. At time-step 5, the dolomite crystal has formed a lower euhedral termination and neighbouring calcite crystals continue growing downward in its place. (c) Small-scale cones illustrate how the corrugation of cone-bounding host-rock strands is analogous at smaller scales-see Figure 13. 

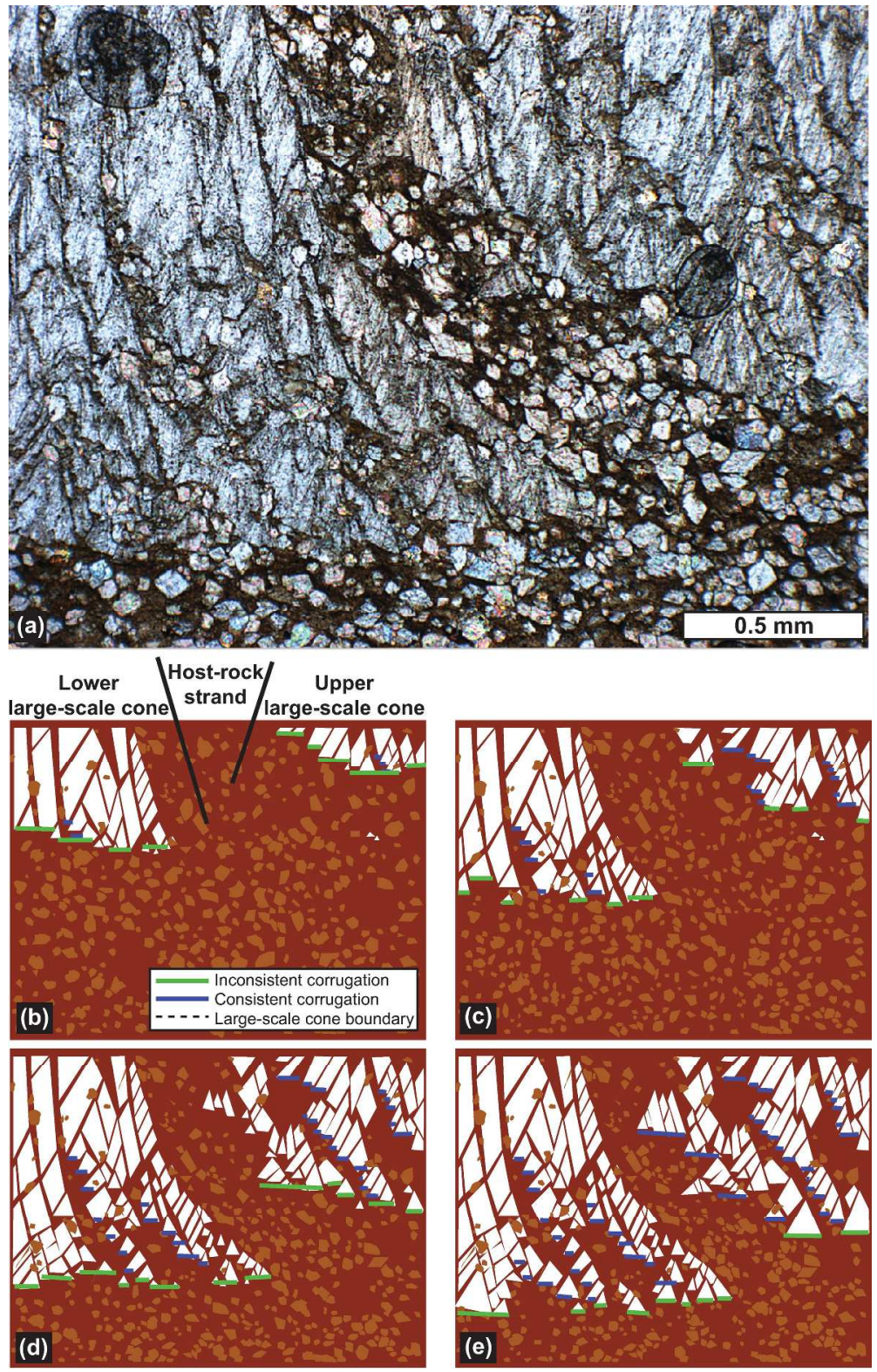

Figure 13. (Colour online) Reconstruction of two interfering, macroscopic cones (Fig. 3). (a) Plane-polarised light image showing the intersection of two large-scale cones. (b-e) Interpretation and reconstruction of (a); (e) shows final state photographed in (a). Host-rock rhombs are pushed downward from growing cones or ensconced within the cone calcite. The higher large-scale cone on right cannot grow laterally into the space occupied by the lower cone on left. The left-side cone, being lower, therefore blocks the growth of the rightside cone, and the boundary between them moves to the right as the cones grow downward. The blocking of the right-side cone produces a consistently corrugated upper surface to the host-rock strand demarcating the cones. The smooth lower surface of the strand defines the top of the left-side cone. The flat bottomsurface of the cone-in-cone is inconsistently corrugated throughout the growth process. Note consistent corrugation of strands between smaller-scale cones, suggesting that the same blocking process occurs at smaller scales. 
2

3

4

5

6

7

8

9

10

11

12

13

14

15

16

17

18

19

20

21

22

23

24

25

26

27

28

29

30

31

32

33

34

35

36

37

38

39

40

41

42

43

44

45

46

47

48

49

50

51

52

53

54

55

56

57

58

59

60 